\title{
Evolution and rupture of vulnerable plaques: a review of mechanical effects
}

This article was published in the following Dove Press journal:

ChronoPhysiology and Therapy

10 April 2013

Number of times this article has been viewed

\section{Pauline Assemat \\ Kerry Hourigan}

Fluids Laboratory for Aeronautical and Industrial Research (FLAIR), Department of Mechanical and Aerospace Engineering and Division of Biological Engineering, Monash University, Melbourne, VIC, Australia
Correspondence: Pauline Assemat Fluids Laboratory for Aeronautical and Industrial Research (FLAIR), Department of Mechanical and Aerospace Engineering and Division of Biological Engineering, Faculty of Engineering, Office I05, Building 36, Monash University, Wellington Road, Clayton, Melbourne, VIC 3800, Australia

Tel +6I 39905 |79|

Email pauline.assemat@monash.edu
Abstract: Atherosclerosis occurs as a result of the buildup and infiltration of lipid streaks in artery walls, leading to plaques. Understanding the development of atherosclerosis and plaque vulnerability is of critical importance, since plaque rupture can result in heart attack or stroke. Plaques can be divided into two distinct types: those that rupture (vulnerable) and those that are less likely to rupture (stable). In the last few decades, researchers have been interested in studying the influence of the mechanical effects (blood shear stress, pressure forces, and structural stress) on the plaque formation and rupture processes. In the literature, physiological experimental studies are limited by the complexity of in vivo experiments to study such effects, whereas the numerical approach often uses simplified models compared with realistic conditions, so that no general agreement of the mechanisms responsible for plaque formation has yet been reached. In addition, in a large number of cases, the presence of plaques in arteries is asymptomatic. The prediction of plaque rupture remains a complex question to elucidate, not only because of the interaction of numerous phenomena involved in this process (biological, chemical, and mechanical) but also because of the large time scale on which plaques develop. The purpose of the present article is to review the current mechanical models used to describe the blood flow in arteries in the presence of plaques, as well as reviewing the literature treating the influence of mechanical effects on plaque formation, development, and rupture. Finally, some directions of research, including those being undertaken by the authors, are described.

Keywords: atherosclerosis, rupture prediction, wall shear stress, structural stress, vulnerable plaques

\section{Introduction}

Atherosclerosis is an inflammatory disease characterized by lipid accumulation underneath the endothelium that lines the walls of blood vessels. In addition to lipid deposition, atherosclerotic progression involves monocyte infiltration, lipid oxidation, ${ }^{1}$ foam-cell formation, smooth-muscle cell migration and extracellular matrix production, to cite just a few processes. ${ }^{2,3}$ The lipid core is separated from the circulating blood by a fibrous cap ${ }^{4}$ composed of smooth-muscle cells, neovascularization, and extracellular matrix. ${ }^{2,5}$ As plaques develop, they can cause luminal constriction (stenotic shape), or may undergo expansive remodeling (aneurysm-like shape) that maintains lumen diameter. ${ }^{6}$ The reason one type of remodeling occurs instead of the other remains a question to be answered. Vulnerable plaques, ${ }^{7}$ prone to rupture or to erosion processes, can undergo a disruption of the fibrous cap, thereby exposing the thrombogenic plaque core to the circulating blood. ${ }^{8}$ Interactions between platelets and the lipid core can induce thrombus formation on the plaque surface, with possible consequences 
including vessel occlusion, myocardial infarction, or stroke. While it is widely accepted that plaque vulnerability is influenced by fibrous cap thickness and size of the lipid core, ${ }^{9}$ these criteria are not sufficient for the prediction of future rupture, as this process also depends on luminal remodeling and on the effects of mechanical stresses. ${ }^{10}$

The complexity of constructing a prediction model for plaque formation, development, and overall rupture arises from the interaction of numerous phenomena (biological, chemical, mechanical) involved in this process. A review of the main biological effects involved in vulnerable plaque formation, as well as the current strategies used to stabilize them, is presented in the recent position paper of the European Society of Cardiology. ${ }^{11}$

An approach adopted by numerous research teams to investigate this problem is to restrict their studies to the influence of the mechanical effects on plaque development, which still leads to a problem of some complexity. Indeed, the influence of hemodynamic parameters (fluid stresses, pressure forces) or of the structural stresses has been shown to provide a clue for the location of plaque development, and is starting to be used for determination of rupture mechanisms (these points will be developed in the following sections). However, the accurate calculation of such parameters is still challenging, and their relative contribution to plaque development continues to be debated. In addition, the literature on plaque progression is very rare, so it is currently difficult to relate plaque morphology in its early stage to its vulnerability over the longer term. The development of numerical and theoretical models, as well as the improvement of biomedical engineering imaging, ${ }^{12-14}$ may provide the means to predict such phenomena; nevertheless, a large number of important physical parameters (geometry, blood viscosity, transmural pressure, blood flow rate, heart beating frequency, blood and tissue density, tissue elasticity properties and boundary conditions) is involved in the implementation of the problem, making the task complex and requiring sometimes unrealistic simplifications. An additional complexity comes from the fact that these parameters vary with the groups under study, with the subjects considered, with their sex and their age, and eventually with the circadian pressure changes. ${ }^{15,16}$ This parameter variation, on which mechanical effects (hemodynamic and structural stresses) are strongly dependent, makes theoretical and numerical model development very challenging.

The purpose of the present article is to review the current knowledge of these parameters as well as of the influence of hemodynamic and structural stresses on plaque formation, development, and rupture.
In the following sections, after a description of the animal models used to mimic human plaque development, a discussion about the physical parameters involved in the mechanical model will be conducted. The hemodynamic parameters and structural stress influence on plaque formation, development, and rupture will then be reviewed.

\section{Animal models}

Different animal models are used to study experimentally vulnerable atherosclerosis development, such as the Watanabe heritable hyperlipidemic rabbit mode ${ }^{17}$ and the porcine model; ${ }^{18}$ however, in recent studies, mice have been the dominant model used for experiments. Different mouse models are available, and their capacity to reproduce vulnerable plaque behavior is discussed in detail in Bond and Jackson, ${ }^{19}$ Schwartz et al, ${ }^{20}$ and Jackson et al. ${ }^{21}$ The most common models are the apolipoprotein E-deficient mouse ${ }^{22}$ (ApoE-/-) and the low-density lipoprotein (LDL) receptordeficient mouse (LDLR-/-) ${ }^{23}$ Under normal diet, the ApoE/ model develops plaques spontaneously, whereas for the LDLR-/- model the process of atherosclerotic plaque formation is much slower. Both mouse models rapidly develop atherosclerosis on a high-fat, high-cholesterol diet. For these models, the location of the plaques on the arterial tree is similar to that for humans (aortic root, lesser curvature of the aortic arch, and branch points of the brachiocephalic, left carotid, and subclavian arteries). ${ }^{24}$ This localization is often associated in the literature with hemodynamic parameters, as reviewed in a following section. An example of plaque formation in an ApoE-/- mouse obtained by X-ray imaging on the Swiss Light Source synchrotron is presented in Figure 1 (mice under 12 weeks of fat diet). The techniques used by our group to reconstruct such an image are described in Assemat et al. ${ }^{25}$ A shortcoming in these models is that plaque rupture, with superimposed thrombosis commonly observed in humans, is rarely observed in the two previously described mouse models ${ }^{26}$ unless surgery is applied on the mice..$^{21,27,28}$

A new mouse model has been developed in the last few years - the SM22 $\alpha$-hDTR ApoE ${ }^{29}$ - which is a transgenic mouse model expressing the human diphtheria toxin receptor in addition to the deficiency of ApoE. When fed a "Western" diet, the mice undergo a thinning of the fibrous cap, a loss of collagen and matrix, an accumulation of cells, and intense intimal inflammation, which are some of the phenomena described in the literature to be characteristic of plaque vulnerability. ${ }^{11}$ Experiments are currently being undertaken in our laboratory to test implications of this 


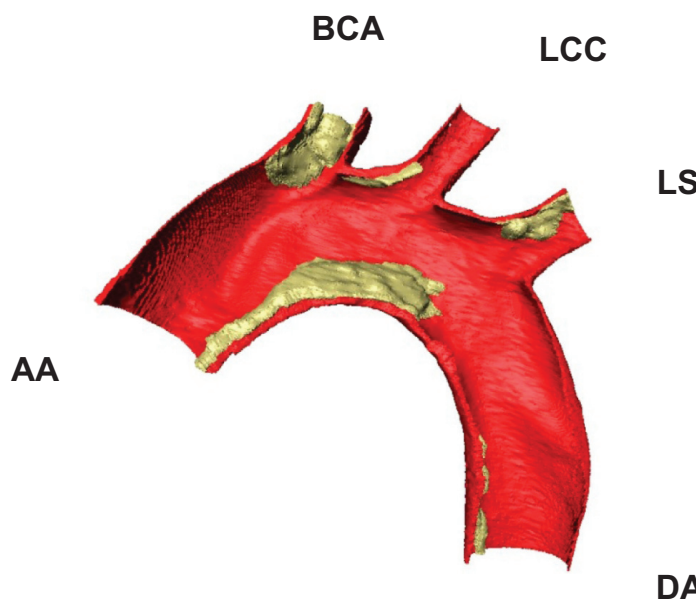

Figure I Half aortic arch segmented from synchrotron data; red corresponds to the artery wall, with atherosclerotic plaque in yellow.

Abbreviations: $\mathrm{AA}$, ascending aorta; DA, descending aorta; $\mathrm{BCA}$, brachiocephalic artery; LCC, left common carotid; LS, left subclavian.

new model on the mechanical phenomena responsible for plaque formation and rupture. In parallel, experiments are being performed on an ApoE-/- mouse model to study stable plaque development.

The physical parameters necessary to implement numerical methods used to achieve the calculation of hemodynamic and structural stresses will be described in the following sections. The influence of these parameters on the mechanical effects will be presented for cases where it has been described in the literature.

\section{Numerical model}

Three equations, with associated initial and boundary conditions, are commonly used to model the coupled blood flow (fluid) and artery motion (solid). The first equation models the incompressibility of the blood flow, the second corresponds to the Navier-Stokes equation and represents the conservation of momentum, and the third is the elastodynamic equation, which describes the motion of the flexible artery wall.

$$
\begin{gathered}
\nabla \cdot U=0 \\
\rho_{f}\left(\frac{\partial U}{\partial t}+(U \cdot \nabla) U\right)=\nabla \cdot \sigma_{f}, \\
\rho_{s}\left(D_{t t} \eta-f_{s}\right)=\nabla \cdot \sigma_{s} .
\end{gathered}
$$

In these equations, $\rho_{f}$ and $\rho_{s}$ represent the fluid and solid density, respectively, $U$ is the 3-D blood velocity field, $\eta$ is the 3-D structure displacement, and $f_{s}$ represents the body forces. The terms $\sigma_{f}$ and $\sigma_{s}$ correspond, respectively, to the fluid and structural stresses. The quantity $\sigma_{f}$ depends on the internal blood pressure distribution $\mathrm{p}$, on $U$ and on the dynamic viscosity $\mu$, whereas $\sigma_{s}$ depends on the elastic properties of the tissues and on the loads applied on them (for example, pressure force, flow velocity, tension). Additional effects could be taken into account as thermal or chemical effects, but they will not be discussed here. In fluid-structure interaction (FSI) prediction models, the most realistic current type of numerical model used to study mechanical effects on plaques, the unknowns that need to be calculated are $U, \mathrm{p}$, and $\eta$, whereas all the other terms correspond to physical parameters experimentally measured and implemented in the numerical codes. In the following subsections, these parameters are discussed.

Concerning the boundary conditions at the blood-tissue interface, the parameters are defined mathematically by the equilibrium of the constraints and the continuity of the velocity field:

$$
\begin{gathered}
\sigma_{f} \cdot n_{f}=\sigma_{s} \cdot n_{s}, \\
U=D_{t} \eta .
\end{gathered}
$$

These boundary conditions are implicitly implemented in the numerical code, and no experimental measurement is necessary to define them. Additional boundary conditions must be applied to the flow and the structure for the problem to be well determined. These conditions are the inlet and outlet boundary conditions. They depend on different physical parameters, such as the physiological blood flow waveform, the natural stretching of the vessels, or the elasticity of the surrounding matrix tissue, so their definition is complex and a current challenge of research.

\section{Physical parameters}

\section{Boundary conditions for the inlet and outlet}

Blood flow in arteries is dominated by unsteady flow phenomena. ${ }^{30}$ Simulating steady flow can be useful in small vessels for which the pulsatile characteristic of the flow has been damped because of the downstream resistance and the distensibility of the vessels. In addition, it can give a first approximation of the distribution of the time-averaged wall shear stress (WSS) ${ }^{31}$ however, most of the time, the use of unsteady flow conditions is necessary to simulate realistic situations.

As a consequence, the imposed boundary conditions applied to solve the fluid part of the problem have a significant influence on the numerical results, and thus accurately defining the boundary conditions is crucial. ${ }^{32}$ 
Boundary conditions are commonly defined in terms of pressure waveforms, velocity waveforms, or flow rate. Such waveforms can be obtained by measuring the velocity field or pressure at particular locations in the arterial tree in live animals. Such measurements can be made by various techniques, including magnetic resonance imaging (MRI) and Doppler ultrasound.

The boundary conditions that need to be applied to calculate the blood flow depend on the characteristics of the vessel of interest. Plaques are mainly observed in three vascular regions of the body: the coronary vasculature, the carotid, and the aortic arch. The treatment of the flow boundary conditions for the carotid and aortic arch is quite similar, whereas circulation beds such as coronary vasculature have a specific hemodynamic condition and require a specific treatment. The complexity of the implementation of numerical methods in the coronary vasculature comes from the different spatial (arterial, venous, capillary system) and temporal scales (short, cardiac cycle changes; long, remodeling and neovascularization) involved ${ }^{33}$ in the modeling, but also from the strong coupling between mechanical and biological effects. ${ }^{34}$ Indeed, the specificity of the coronary circulation is the compression of the blood vessels as the heart contracts, combined with the necessity to provide continuous perfusion to match metabolic rates (such as oxygen). ${ }^{33}$ During the systole, the contracting myocardium generates a high level of intramyocardial pressure that compresses the coronary microvasculature, thereby impeding blood flow. Conversely, during diastole (much longer than the systole), intraventricular pressures transmitted into the left ventricular wall exert a small compressive force on the intramural vasculature, creating "waterfalls" at the level of the arterioles and the venules. ${ }^{35}$ Another characteristic of the coronary vasculature is the autoregulation process. This corresponds to the intrinsic tendency of the vasculature to maintain constant blood flow despite changes in perfusion pressure ${ }^{34}$ during a constant metabolism. These adjustments correspond mainly to a change in the diameter of the arterioles and microvessels. The extensive reviews of Waters et al, ${ }^{33}$ Westerhof et al, ${ }^{34}$ and Duncker and Bache ${ }^{35}$ give a detailed insight of the complexity of the flow in coronary vasculature. In particular, Waters et $\mathrm{al}^{33}$ recently reviewed current challenges to model accurately coronary vascular biomechanics.

Concerning the aortic arch, the temporal and spatial scale ranges are more homogeneous, and boundary conditions are often directly extracted from in vivo measurements. In addition, compared to the coronary vasculature, the motion of those arteries is more independent of biological effects, and their behavior is mainly subject to mechanical loads. For animal studies, measurements are typically taken in unconscious animals, and anesthesia is known to reduce heart rate and hence cardiac output. Therefore, the waveforms for anesthetized animals are typically scaled to obtain the velocity waveform in a conscious animal. This technique has been employed by Huo et al; ${ }^{36}$ they used an inlet velocity profile measured from a Doppler flow meter that was scaled based on ratios of heart rates and time-averaged flow rates in conscious and anesthetized mice. Van Doormaal et $\mathrm{al}^{37}$ also used a scaling technique to obtain inlet boundary conditions from aortic root velocities measured in anesthetized mice, using phase-contrast MRI. In a separate study involving mice, scaling was performed by compressing the diastolic portion of the cardiac cycle, but not the systolic, since it was noted that the decreased cardiac output during anesthesia is predominantly due to decreased heart rate rather than stroke volume. ${ }^{38}$ However, not all studies have used an anesthetizedto-conscious scaling technique to obtain the inlet boundary conditions. Trachet et $\mathrm{al}^{39}$ employed an inlet velocity waveform from humans that was scaled in magnitude and time to match mouse physiology. In addition, Janssen et $\mathrm{al}^{40}$ demonstrated that cardiac output can be measured reliably in conscious mice using transit-time flow and electromagnetic probes placed in mice by surgery. In addition to velocity and flow rate, boundary conditions may be defined by pressure. In a study of the idealized human aortic arch, Vasava et $\mathrm{al}^{41}$ employed a pulsatile pressure pulse as the inlet boundary condition.

Concerning the outflow boundary conditions, outflow velocities could also be measured in live animals, and scaled velocity waveforms directly applied to the boundaries. However, in reality, the velocity waveforms in the abdominal aorta arrive later than those measured earlier in the arterial tree, due to interactions between the blood flow and artery wall motion. ${ }^{42}$ For this reason, in many numerical simulations, rigid walls are assumed; thus, to ensure mass conservation, it is considered that the sum of the inflow and outflow must be equal so that the velocity waveforms measured in vivo cannot be directly applied. In order to overcome this problem, Trachet et $\mathrm{al}^{42}$ redistributed the flow (from Doppler flow measurements) across all inlets and outlets using a weighting scheme. In other studies conducted in mice, the outlet boundary conditions were based on a percentage of the flow rate entering the aortic root. ${ }^{31,37-39}$ These studies assume that flow division remains constant throughout the pulse. Huo et $\mathrm{al}^{36}$ used pressure as a boundary condition when studying pulsatile flow through the mouse aortic arch. The pressure at each outlet was obtained 
based on a scaling law, using pressure measurements from the common carotid artery. Pulsatile pressure profiles were also employed as the outlet condition in a numerical study in the human aortic arch. ${ }^{41}$ In Lantz et al, ${ }^{43}$ scaled mass ratios were applied at the outlet of the connected arteries, and an impedance boundary condition applied at the end of the descending aorta. This boundary condition is represented by a Windkessel model and describes the relationship between the aortic outflow and a physiologically relevant aortic pressure condition. ${ }^{44}$ To our knowledge, one of the most complete studies conducted on the boundary conditions in a complex geometry is the recent work of Moireau et al. ${ }^{45}$ In this study, the flow inlet boundary condition was a volumetric waveform, whereas a "coupled multidomain" approach is used for the outlets where threeelement Windkessel models are implemented.

The previously described inlet and outlet boundary have been associated with numerical models that consider rigid walls (except the two last references), ${ }^{43,45}$ however, for a more realistic model, a coupled solid motion must be taken into account and boundary conditions on the solid must be implemented as well.

Most of the studies that take into account the fluid and structure coupling consider that the tissue is fixed at the inlet and outlet ${ }^{46}$ or that structure motion is prevented in the axial direction. ${ }^{47}$ An illustration of the influence of such boundary conditions is shown in Figure $2 .{ }^{48}$ Here, the geometry was obtained by synchrotron X-ray computed tomography imaging. Pressure was increased from $100 \mathrm{mmHg}$ to $105.2 \mathrm{mmHg}$. The simulations have been performed with the AnSys CFX for the fluid solver, and AnSys Mechanical Parametric Design Language has been used for the structural solver. The two-way FSI coupling between the structural and fluid solvers is achieved within a coupling iteration loop (AnSys Multi-field), where field variables (displacement and forces) are exchanged between both solvers. The hexahedral mesh was achieved using AnSys ICEM CFD software. It is observed in Figure 2 that fixed boundary conditions for the solid generate a bulging; therefore, more realistic boundary conditions must be taken into account to predict the deformation of the artery wall in in vivo conditions.

To this aim, natural traction equilibrium can be implemented. ${ }^{49,50}$ An improved model of boundary conditions for the tissue has been implemented by Lantz et al. ${ }^{43}$ In their study, the geometry is considered to be constrained in axial direction at the inlets and outlets, but it is allowed to evolve in the radial and circumferential directions at all locations. In addition, as the tissue surrounding the aorta is expected to have a damping effect on the aortic wall movement, this effect is taken into account by applying a linear elastic support boundary condition on the external face of the aorta. In Moireau et $\mathrm{al}^{45}$ the authors note that the descending thoracic aorta is longitudinally tethered by the spine, whereas the ascending aorta is less constrained by external tissues and structures. To take into account this variety of phenomena, they consider Robin boundary conditions on the external surface of the artery:

$$
\sigma_{s} \cdot n_{s}=-k_{s} \eta-\mathrm{c}_{s} \frac{d \eta}{d t}-p_{0} n_{s}
$$

In this equation, $k_{s}$ and $\mathrm{c}_{s}$ depend on space and model, respectively: an elastic and a viscoelastic response of the surrounding tissue matrix. Similar boundary conditions are implemented on the structure outlet. Concerning the inlet (aortic arch root), large displacements of the aorta due to heart-beating motion are taken into account through similar Robin-type boundary conditions:

$$
\sigma_{s} \cdot n_{s}=-k_{s}\left(\eta-\eta_{b}\right)
$$

Here, $\eta_{b}$ is a prescribed displacement that can be extracted from in vivo image data.
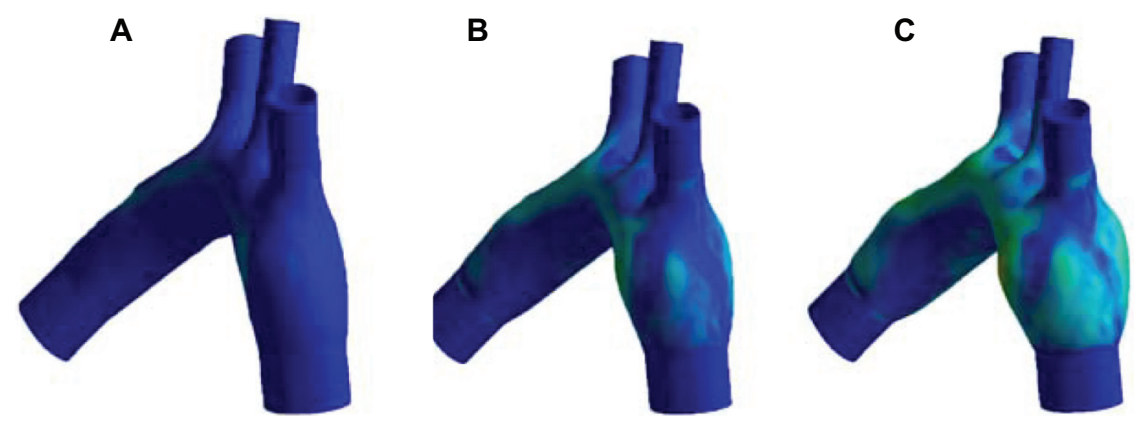

Figure 2 (A-C) Deformation of artery walls under pressurization.

Notes: Isocontours of structural stress are represented. The geometry has been obtained by synchrotron $\mathrm{X}$-ray imaging. The mice tissues were perfusion fixed with Karnofsky's fluid ( $2 \%$ glutaraldehyde $+4 \%$ paraformaldehyde in $0.1 \mathrm{M}$ phosphate buffer, $\mathrm{pH} 7.4$ ) at a mean pressure of $100 \mathrm{mmHg}$. The tissue is consider isotropic, with a Young's modulus of $E=20 \mathrm{kPa}$. (A) $\mathrm{p}=100 \mathrm{mmHg}$; (B) $\mathrm{p}=102.6$; (C) $\mathrm{p}=105.2 \mathrm{mmHg}$. 
Besides the question of the implementation of realistic boundary conditions, the numerical coupling between the fluid and structural solvers is far from being trivial. In this approach, three main difficulties have to be overcome: the implementation of large deformation, the implementation of thick structure with various elastic properties (the plaque generates a thickening of the artery wall and the structural stresses over the thickness need to be known), and the strong coupling between the fluid and the structure dynamics. The first point implies that the numerical methods used to implement the fluid-structure coupling need to enable large mesh deformation or to be able to track the fluid solid interface without changing the basic mesh. Mesh-deformation methods are often preferred in commercial codes such as AnSys or ADINA, but also in open-source codes such as OpenFOAM. This approach was used, for instance, by Lantz et a ${ }^{43}$ to study the influence of moving wall on the calculation of WSS in human aortic arch. Huang et $\mathrm{al}^{51}$ and Leach et $\mathrm{al}^{52}$ also used this approach to study plaque rupture in human carotid arteries. Another method that takes into account the mesh deformation is the Arbitrary Langrangian Eulerian method implemented by Moireau et $\mathrm{al}^{45}$ to study patient-specific aortic arch deformations. The second type of method often used in bioengineering comprises front tracking/capturing techniques, such as immersed boundary methods and levelset methods, implemented, for example, at the Johns Hopkins University to simulate flow in the left ventricle.$^{53}$ However, the main limitation of these two powerful methods in the present context comes from the approximation of the vessel wall as a membrane, so that plaques cannot be taken into account. The last point to be addressed is the time coupling between the fluid and the solid. Most of the current methods use iterative methods to transfer the loads between the fluid in the solid phase within one time-step iteration. In reality, the fluid and solid are fully coupled so that this iterative process induces additional numerical approximations within the temporal scheme. In order to prevent such approximations, direct methods, such as the coupled momentum method ${ }^{45}$ or the simultaneous solution approach (ADINA), can be implemented.

\section{Geometrical dimensions}

As discussed previously, even if a specific plaque distribution pattern is recovered between subjects, ${ }^{11}$ the geometry of the plaques depends on the species, sex, ${ }^{21}$ and specific morphology of the subjects considered. The question of the impact of the geometrical parameters is then important for the prediction of plaque formation and rupture. As a consequence, determining the geometry with accuracy is a crucial question related to the advancement of imaging techniques. ${ }^{12-14}$

Currently, the main techniques used in the literature are MRI, ${ }^{31,49}$ ultrasound, ${ }^{31,54}$ angiography, ${ }^{55}$ computed tomography, ${ }^{45,56}$ and microcomputed tomography. ${ }^{25,57,58}$ An example of the geometry obtained by computed tomography and used for computational simulations is given in Figure 3. ${ }^{45}$ A recent review of the current imaging techniques used in vivo and in vitro is given in Fleg et al. ${ }^{59}$ Concerning the resolution of the cited methods for in vivo measurements,
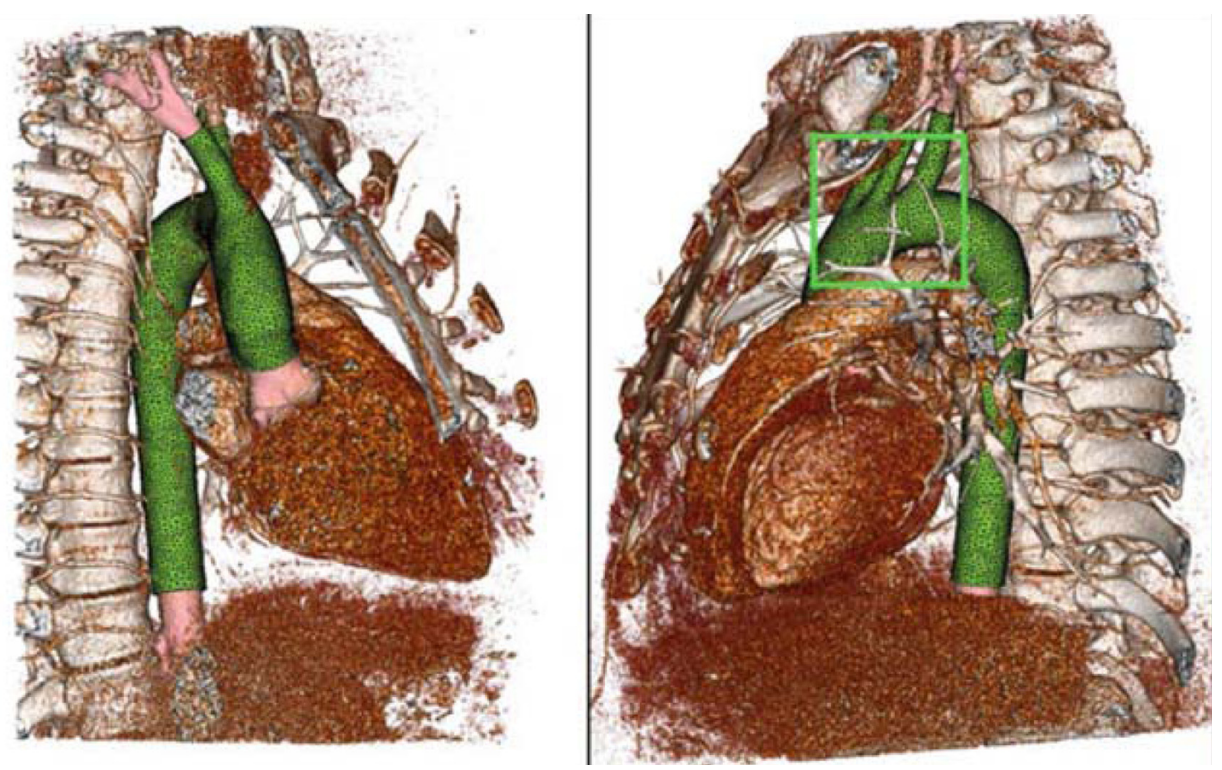

Figure 3 Computed tomography volume rendering, segmentation, and associated computational mesh. Reproduction from Moireau et al. ${ }^{45}$ 
MRI, used extensively for clinical applications, achieves a spatial of order of a few millimeters ${ }^{60-64}$ up to $0.5 \mathrm{~mm}^{65}$ for a temporal resolution ranging between 10 and $57 \mathrm{~ms}$. Another extensively used imaging technique is ultrasound imaging, which can provide a very good temporal resolution. However, this method is limited by its spatial resolution and overall penetration depth, which decreases (from $30 \mathrm{~mm}$ to a few millimeters) when higher spatial resolution is required $(0.7 \mathrm{~mm}$ to $40 \mu \mathrm{m}) .{ }^{65} \mathrm{X}$-ray technology (angiography when associated with the visualization of blood vessels) is also a commonly used technique $(0.6 \mathrm{~mm}$ for the spatial resolution and $210 \mathrm{~ms}$ for the temporal). ${ }^{66}$ Recently, the use of synchrotron monochromatic X-ray radiation ${ }^{67}$ enabled the authors to reach a spatial resolution of $8 \mu \mathrm{m}$ and a temporal resolution of $33 \mathrm{~ms}$ in angiograms obtained from an adult rat. This technique provides only 2-D images, a restriction that can be overcome using the promising microcomputed tomography technique. Dubsky et $\mathrm{al}^{68}$ used it to image lung motion of mice and newborn rabbits. The spatial resolution reached is $20 \mu \mathrm{m}$ for a temporal resolution of $33 \mathrm{~ms}$. In the present context, one of the challenges is to obtain images of atherosclerosis in the early stage of development to prevent eventual complications, a purpose that can be achieved using high-resolution imaging such as microcomputed tomography; however, this method is risky, and other techniques are usually preferred for in vivo imaging. In in vitro imaging techniques, spatial resolution up to $23 \mu \mathrm{m}$ can be obtained with MRI, ${ }^{69,70}$ and up to $1.7 \mu \mathrm{m}$ with microcomputed tomography (recent results obtained by our group at the Swiss Light Source, Figure 4). In addition to these approaches, new techniques are emerging, such as nanoparticle technologies ${ }^{71,72}$ coupled to traditional imaging methods (eg, MRI). By this technology, the core of the plaque can be tracked using specific nanoparticles embedded in a convenient product that targets the cells needed to be observed. In the context of atherosclerotic diseases, the targeted cells are the macrophages, which deposit in the lipid core.

Concerning the effects of the dimensions on the hemodynamic parameters, Trachet et $\mathrm{al}^{39}$ discussed the impact of the size of the aortic arch at different times of a mouse's life (from embryonic stage to 9 months old) and calculated the WSS associated. They showed that the size has a substantial impact on the WSS, a fact that can considerably change the stresses applied on the plaque and therefore its vulnerability. In a separate study, Feintuch et $\mathrm{al}^{31}$ discussed the effect of the scaling between humans and mice, and found that the wall stresses induced by the blood flow are higher in amplitude and more spatially uniform in mice than in humans. This result can be explained by the difference in the Reynolds numbers, a dimensionless parameter that characterizes the ratio of inertial forces to viscous forces, and which varies from 100 in mouse aortic arch to 1500 in human aortic arch in the steady-flow simulations of Feintuch et al. ${ }^{31}$ For a human aortic arch, Lantz and Karlsson ${ }^{73}$ indicate, based on MRI measurements, that the instantaneous Reynolds number ranged from 150 at the late diastole to 6500 at the peak systole. The mean Reynolds number is found to be around 1200. Consequently, the resulting flow in humans is more complex and eventually turbulent ${ }^{64}$ (see next section); however, zones of low WSS are located in the same areas of the arterial tree for both the species, a criterion related to plaque-formation site location. To underline the importance of the geometry in

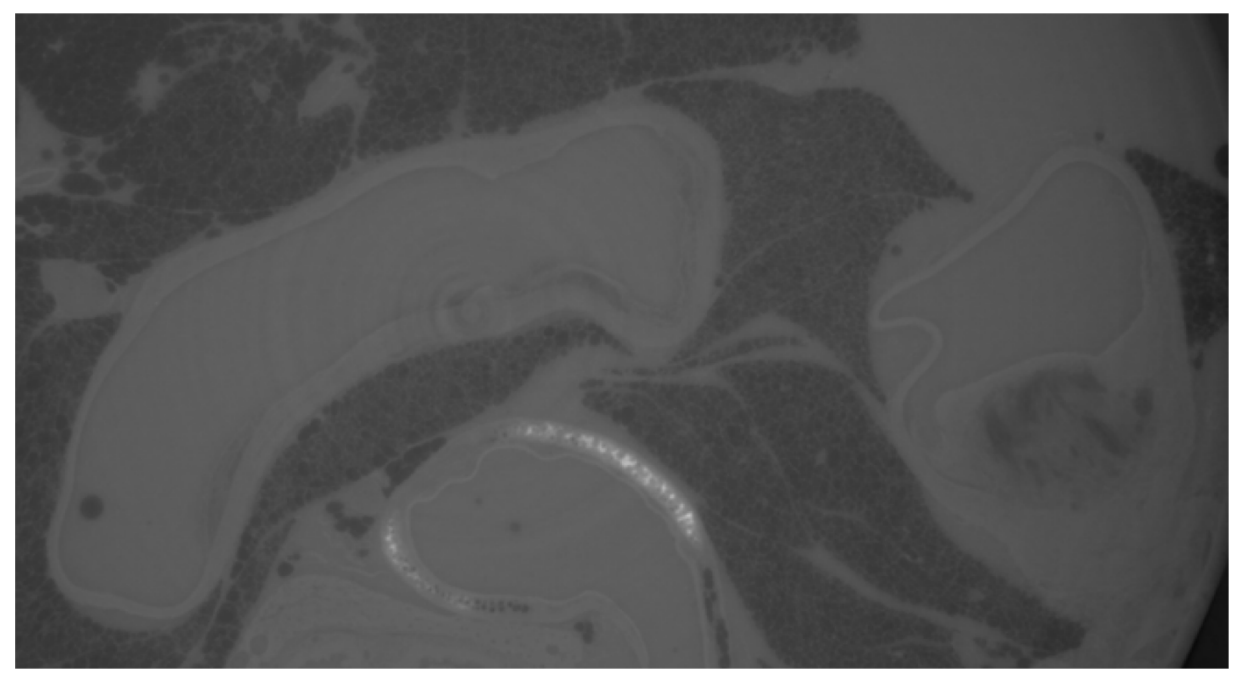

Figure 4 Two-dimensional section of an $\mathrm{ApoE}(-/-)$ aortic arch obtained by computed tomography.

Notes: The high-resolution details obtained for the plaque in the ascending aorta can be seen on the right of the figure. Dark zones correspond to lung tissue. 
the plaque development process, Tomita et al, ${ }^{74}$ continuing from the work of Zhu et al, ${ }^{38}$ studied the plaque development in ApoE-null mice of different genetic backgrounds (29S6/ SvEvTac and C57BL/6J). They found that the geometric differences (broader inner curvature for the first, and larger vessel diameter for the second) resulted in a huge difference in the size of the developed plaques in the different mouse strains.

\section{Fluid physical properties}

The fluid density $\rho_{f}$ is quite independent of the species and of the age considered, and is equal to $1060 \mathrm{~kg} / \mathrm{m}^{3}$ in most of the studies reviewed in the present paper. ${ }^{75}$ For the viscosity, the question of non-Newtonian effects has been raised, ${ }^{76,77}$ and a Carreau viscosity model ${ }^{78-81}$ or a power-law model ${ }^{82}$ are often preferred to treat non-Newtonian effects in large arteries. In Liu et $\mathrm{al},{ }^{81}$ the authors indicate that the non-Newtonian effects can be significant in the study of mass transport, in particular in the atherogenic-prone areas where luminal surface LDL concentration is high. In Johnston et al, ${ }^{82}$ five non-Newtonian models were compared and the use of the generalized power-law model advised to capture the physics of the problem in zone of low shear stress; however, most of the studies reported in the present paper consider the blood as Newtonian, a reasonable assumption provided the shear rate $\partial \mathrm{U} / \partial r$ is greater than $150 \mathrm{~s}^{-1} .{ }^{83}$ This condition is expected to be fulfilled in large arteries under normal activity.

In respect of the numerical model for the fluid, the question of the transition to turbulence is raised, as specific numerical methods need to be used to treat the complexity of the flow in a reasonable computational time. In order to determine the critical Reynolds number at which the flow becomes turbulent under physiologically realistic conditions, Peacock et $\mathrm{al}^{84}$ investigated steady and oscillating flow in glass tubes of different diameters. As expected, they found a critical Reynolds number for steady flow of around 2000. For the oscillating flow, they found an empirical law that relates the critical Reynolds number and the Womersley (pulsatile flow forces versus viscous forces) and Strouhal numbers (oscillatory inertial forces versus convective inertial force). They found that the critical Reynolds number increases when the Womersley number increases. According to this study, the critical Reynolds numbers related to physiologically realistic conditions are: in the human aortic arch, 5500 (rest), 9800 (exercise); and in the human left coronary 1650 (rest), 2650 (exercise). However, these experiments have been undertaken in rigid tubes, so the turbulence transition in an elastic vessel is still a question under debate. In a recent study, Stalder et al ${ }^{64}$ investigated the turbulence of the blood flow in the aortic arch of 30 volunteers under rest condition. It was found that flow instabilities of the laminar flow are likely in ascending and descending aorta but unlikely in the arch, and that this transition is also sex-dependent.

In the case of the numerical methods implemented for turbulent situations, Lantz and Karlsson ${ }^{73}$ and Lantz et al ${ }^{85}$ used large-eddy simulation methods to study the blood flow in the human aortic arch. This method is generally more accurate than the commonly used Reynolds-averaged Navier-Stokes methods in the field of turbulence. For small animals such as mice, the characteristic mean Reynolds number involved is much smaller than in humans $(<100),{ }^{31}$ and transition to turbulence is not expected, so direct numerical simulation methods can be used.

\section{Solid physical properties}

Tissue and lipid-core density have been measured by Shinohara et $\mathrm{al}^{86}$ for male ApoE-/- mouse atherosclerosis. The mass density of the lipid area was found to be lower $(1.011 \pm 0.001766 \mathrm{~g} / \mathrm{mL})$ than that of smooth-muscle area or collagen area $(1.057 \pm 0.001407$ and $1.080 \pm 0.001794 \mathrm{~g} / \mathrm{mL}$, respectively). To our knowledge, numerical calculations taking into account these variations have not yet been conducted, so the influence of this physical parameter on hemodynamic or structural stresses has not yet been identified.

A more complex question concerns the determination of the elastic properties of the vessels. Indeed, the tissue is an anisotropic hyperelastic material, so the parameters that define elastic properties depend not only on the type of tissue considered (intima, media, adventitia, fibrous cap, or lipid core) $)^{87}$ but also on the direction considered (radial, circumferential, or axial) ${ }^{88}$, on the area of interest in the arterial tree and on the loading applied. In addition, vessels are preconstrained structures, a fact observed by the reduction of the length and of the perimeter of the vessel during excision. This effect must be taken into account, in addition to the previously cited ones, during the modeling of arterial elastic properties. In his book Biomechanics: Mechanical Properties of Living Tissues, ${ }^{89}$ Fung gives a good description of these different aspects.

On the question of the preconstraints, two parameters must be determined: the stretch ratio in the longitudinal direction obtained measuring the shrinkage during the dissection of the vessel, and the opening angle obtained when a section (ring) of vessel is cut. Fung ${ }^{89}$ underlines that attention must be paid in the determination of these parameters, as they depend on the location in the arterial tree. In Fung, ${ }^{90}$ it is indicated that 
the stretch ratio in rabbit arteries varies from 1.6 in the carotid to 1.4 for the upper abdominal aorta, whereas Fung and $\mathrm{Liu}^{91}$ showed that the opening angle in normal rats varies from $160^{\circ}$ in the ascending aorta and $90^{\circ}$ in the arch to $60^{\circ}$ in the thoracic region. Details of the use of these parameters for the modeling of the vessel properties are not discussed here, but the reader can refer to Lee et al, ${ }^{92}$ Holzapfel et al,,${ }^{93}$ or Raghavan et $\mathrm{al}^{94}$ for additional information on this issue.

Concerning the variation of the elastic properties as a function of the load applied (pressure, tension, and flow, for instance), one can refer to Martinez et $\mathrm{al}^{95}$ and Lee et al. ${ }^{92}$ In these papers, the authors measure the evolution of the longitudinal and circumferential stretch ratio as a function of internal pressure during an inflation test. This procedure enables them to approximate the stress-strain evolution, characteristic of the elastic properties of a material, by a mathematical hyperelastic model. In the literature, different types of mathematical models are used. The most popular ones are the Fung model ${ }^{92,96}$ and the Mooney-Rivlin model. ${ }^{97-99}$ The models can be of exponential (Fung), polynomial (MooneyRivlin), or logarithmic form. ${ }^{100}$ An extended review of these models is given in Humphrey ${ }^{101}$ and Holzapfel et al. ${ }^{93}$ More elaborate models that take into account the morphological structure of the artery, ie, wherein the collagen fibrils are embedded in concentrically arranged elastin/smoothmuscle membranes, ${ }^{102,103}$ have been also developed. For the most recent models, the aim is to take into account a higher degree of complexity. For instance, in Zulliger and Stergiopulos, ${ }^{104}$ the stiffening of the aorta with progressing age is investigated. On the question of the stiffening of the arteries due to age, Astrand et a $1^{105}$ used an in vivo technique to study the stiffening of elastin and collagen. They found that the stiffness of elastin increased despite the decrease in elastin content and that at high physiological pressure, there was a stiffening of collagen. They also put forward a sex difference with far fewer age-related effects for women. In Valentin et al, ${ }^{106}$ the authors suggest that the loss of elastin and vasoactive function and collagen stiffening are fundamental for the description of aortic aging processes. Unfortunately, most of the constitutive models treat the arterial wall as a single layer, and as described in Fung's book, ${ }^{89}$ the elastic vessel properties depend on the location in the constitutive layers of the vessel wall (intima, media, adventitia). In a study of rat arteries, ${ }^{107}$ the Young modulus E was measured in the ascending aorta and found to be $\mathrm{E}=447 \mathrm{kPa}$ for the intima-media layer and $\mathrm{E}=112 \mathrm{kPa}$ for the adventitia layer. The same multiplying factor was found in the descending aorta, with $\mathrm{E}=248 \mathrm{kPa}$ for the intima-media and $\mathrm{E}=69 \mathrm{kPa}$ for the adventitia layers. According to this observation, some researchers developed two-layer constitutive anisotropic models to describe the elasticity of the variety of material found in vessel walls. ${ }^{93,108,109}$ Unfortunately, none of these models adapted for healthy arteries can be applied directly to more complex situations, such as arteries with atherosclerotic plaques. As a consequence, in the last few years, different devices have been used to measure elastic properties of atherosclerotic plaques, such as compressive cyclic loading and stress-relaxation testing, ${ }^{110}$ and torsional rheometer testing of synthesized lipid pools. ${ }^{111}$ These techniques require moving the plaques from their natural environment and treating them as a homogeneous material. Hence, they do not account for the fact that the close proximity of stiff and compliant materials can lead to stress concentrations where rupture may occur. ${ }^{112}$ To overcome this restriction, Matsumoto et $\mathrm{al}^{113}$ used a scanning microindentation tester to measure the radial stiffness of the smooth-muscle cell layer and elastic laminae of a porcine aorta. Also, Oie et $\mathrm{al}^{114}$ used a tactile mapping system to measure the axial stiffness of the media and of the elastin. More recently, atomic force microscopy has been used on ApoE-/- mouse aorta samples ${ }^{115,116}$ to undertake mapping of the elasticity properties of the different material present in the artery wall and in the atherosclerotic plaques. This method is of particular interest in determining the elastic properties of the lipid core $\left(1.5 \pm 2 \mathrm{kPa}^{115}\right.$ and $\left.5.5 \pm 3.5 \mathrm{kPa}^{116}\right)$.

The interest in determining precisely the physical parameters involved in the numerical model presented previously is to calculate accurately the blood velocity field, the pressure distribution in the lumen, and the deformation of the vessel walls. The knowledge of these quantities permits the calculation of parameters used to define criteria for plaque formation, development, and rupture processes. An overview of these parameters and their relation to the plaque evolution is presented in the following section.

\section{Plaque formation}

Atherosclerotic plaques are found at particular sites in the arterial tree and their location depends largely on hemodynamic factors such as wall shear stress (WSS). ${ }^{2,117}$ Here, the literature on the distribution of the plaque in the arterial tree and its dependence on the hemodynamic factors will be reviewed. Most of the studies reported are related to plaques in the carotid or aortic arch.

Atherosclerotic plaques are commonly found on the inner curvatures of arteries and near bifurcations. To explain this phenomenon, numerous studies have investigated hemodynamic parameters. 
Hemodynamic parameters are influenced by the geometric irregularities of the arteries, with low WSS (unidirectional WSS with a low time average), commonly observed on inner curvatures of arteries and oscillatory WSS (bidirectional WSS with a low time average) in regions of bifurcations. ${ }^{118} \mathrm{WSS}$ is defined as the product of the viscosity and the normal derivative of the blood velocity at the wall $\left(\mathrm{WSS}=\mu \partial \mathrm{U} /\left.\partial r\right|_{w}\right)$, an equation that underlines the importance of the calculation of the blood velocity field. In the literature, however, due to the oscillatory nature of the blood flow, the calculation of time averaged wall shear stress ( TAWSS $=\frac{1}{T} \int_{0}^{T}\left|\tau_{w}\right| d t$, where $T$ is a cardiac cycle period, $\tau_{w}$ is the instantaneous WSS vector and $t$ is time) is often preferred and used to calculate the oscillatory shear index (OSI), discussed later in the present article, which describes the cyclic departure of the WSS vector from its predominant axial alignment. Caro et $\mathrm{al}^{119}$ suggested that the distribution of atherosclerotic lesions corresponds to regions of the arterial wall that experience low shear rate, and proposed that low WSS leads to atherosclerosis development through altering cholesterol transport. A significant correlation between low WSS and an increased rate of atherosclerosis progression was shown in humans using quantitative angiographic analysis and computer simulations. ${ }^{120}$ Stone et al ${ }^{121}$ performed an in vivo study involving humans with stable coronary artery disease and demonstrated that plaque progression occurs in regions of low WSS and may be accompanied by either expansive or constrictive remodeling. The association between low WSS and atherosclerosis is now widely accepted, and efforts are being made to provide imaging techniques that enable it to be measured in vivo. ${ }^{122}$ Low WSS has been shown to upregulate both adhesion molecules that attract leukocytes and growth factors that promote smooth-muscle cells to proliferate and migrate. ${ }^{2}$ Using porcine culture endothelial cells, Warboys et al ${ }^{123}$ showed that acute application (1 hour) of shear stress increases the permeability of the endothelial monolayer, whereas chronic application (1 week) induces the opposite phenomenon, reducing the permeability and therefore the infiltration of macromolecules responsible for plaque formation. This provides a molecular explanation for the role of hemodynamics in atherosclerosis, since both of these processes are critical in plaque formation.

Other hemodynamic factors are also thought to play a role in plaque development, including the OSI, $\left(\right.$ OSI $\left.=\frac{1}{2}\left(1-\left|\frac{1}{T} \int_{0}^{T} \tau_{w} \mathrm{dt}\right| / \frac{1}{T} \int_{0}^{T}\left|\tau_{w}\right| \mathrm{dt}\right)\right)$, which describes the alignment of instantaneous WSS vector with average WSS vector, and the WSS gradient (WSSG), corresponding to spatial WSS variation. Concerning the oscillatory shear, the correlation between low WSS, high OSI, and plaque formation site is still under debate. A laser Doppler velocimetry study involving pulsatile flow through a model human carotid bifurcation revealed that while plaques grow in regions of low WSS, atherosclerosis development is enhanced by oscillations in WSS. ${ }^{124}$ These findings have been supported by others, with Huo et $\mathrm{al}^{36}$ demonstrating that regions of low WSS and high OSI correlate with regions prone to atherosclerosis development in a numerical study involving the mouse aorta and with Liu et al ${ }^{81}$ for a human aorta. Recently, Thim et al ${ }^{125}$ showed that both low WSS and oscillatory shear stress seem to be necessary for plaque formation, a conclusion supported by the results of Rikhtegar et al. ${ }^{126}$ In a numerical study of human aortic arch, Lantz et al ${ }^{85}$ report an inverse relation between OSI and time-average WSS, sustaining the theory of the correlation between low WSS and high OSI zones; however, the authors report additional situations where both the OSI and time-average are high in sites prone to atherosclerotic formation. The question of the necessity of low WSS to generate plaques is also raised in Hoi et al, ${ }^{58}$ where zones of high OSI are shown to be in qualitative agreement with plaque spatial distribution in LDLR-/- mouse aortic arches. However, plaques have been found in zones where time-average WSS is not necessarily low. In this study, the authors suggest that oscillatory flow could be an atherogenic stimulus independent of the low WSS. This correlation is also questioned in Van Doormaal et al..$^{37}$ In Harloff et al, ${ }^{60}$ the authors performed a study of the WSS and the OSI in the aortic arches of 62 stroke patients. They found that high OSI was not directly correlated with complex plaque sites, whereas a better correlation was found with regions of low WSS; this result is in apparent contradiction with previous ones, but was obtained on a larger cohort.

Furthermore, the phenotype of the developing plaque has been shown to depend on the combination of these hemodynamic factors. In an in vivo study in mouse carotid arteries, stable plaques were shown to develop in regions of oscillatory WSS and vulnerable plaques in regions of low WSS. ${ }^{118}$ In an in vitro experiment investigating the responses of vascular endothelium to disturbed flow, low WSS and large WSSG were found near reattachment sites. By observing the responses of the endothelial cells, it was proposed that WSSG may induce changes in endothelial cell function and contribute to atherosclerosis development. ${ }^{127}$ A review of the endothelial layer behavior with shear stress is given in Chiu and Chien. ${ }^{128}$ Lei et al ${ }^{129}$ suggested that WSSG may be the best indicator of atherosclerosis, according 
to a numerical study involving branching arteries in rabbits. Farmakis et $\mathrm{al}^{55}$ also suggested the use of WSSG as a criterion for plaque localization, as even if spatial distribution of WSSG is similar to WSS spatial distribution, WSSG regions are extended to larger areas, in agreement with observations of lesions reported in previous studies. ${ }^{55}$ Recently, Michell et al ${ }^{130}$ showed that high pressure is related to leukocyte adhesion along the endothelium, a phenomenon related to an early stage of the plaque-formation process. This result underlines the difficulty of determining the exact contributions of various hemodynamic parameters, such as WSS, OSI, WSSG, and pressure forces.

In addition, the computational studies reported so far consider the artery as a rigid wall. This assumption is discussed by Lantz et al, ${ }^{43}$ who showed that the wall motion had a low influence on the time-average WSS but could have a more visible influence on instantaneous WSS values. LawrenceBrown et al ${ }^{131}$ suggested that stress in the structure could also be a potential mechanism responsible for plaque-formation processes.

Thus, whilst it is largely agreed that atherosclerotic development occurs in regions of disturbed flow, the influence of the different mechanical effects on plaque formation and their relative participation in the process is still a question under debate.

\section{Plaque development}

While there have been many computational studies in healthy arteries associating the development of plaque with regions of low WSS and other hemodynamic parameters, the hemodynamics in the presence of atherosclerotic plaques are less well understood. Most of the studies conducted on this problem consider rigid stenosis; $;^{132-137}$ however, even under this restriction, the blood flow is shown to be complex. Figure 5 indicates such a behavior for a model of axisymmetric stenosis in a perspex tube. ${ }^{134}$ The trajectories in the flow are observed by fluorescein dye. This complexity observed in a simple model indicates the more complex flow change expected in real arteries with plaques. Growing efforts are being made to enable the measurement of flow characteristics in vivo. Particular attention has been paid to develop techniques that permit the measurement of WSS. ${ }^{138,139}$

From the numerical point of view, Chaichana et al ${ }^{140}$ performed a computational fluid-dynamics analysis involving model plaque in left coronary arteries to investigate the effect of plaque on the hemodynamics of flow. The presence of plaque was found to alter the pressure gradient, with higher gradients in the stenotic regions that may contribute to plaque rupture. Furthermore, the plaque was found to induce low velocity in the region surrounding the plaque. These low-flow regions are associated with low WSS, and may contribute to plaque progression. ${ }^{140}$ In another similar study, plaques at the coronary bifurcation were found to induce low WSS in coronary side branches. ${ }^{141}$ Lee et $\mathrm{al}^{56}$ studied the flow around a plaque grown in a human carotid bifurcation. They found, in addition to vortex formation downstream of the stenosis, high WSS on the stenosis during the systole, and high spatial gradient of WSS in the region of flow separation. Similar peaks of WSS in ApoE-/- mouse stenosis were found by Hough et $\mathrm{al}^{142}$ during the systole. Figure 6 reproduces this result for a healthy and pathological brachiocephalic artery. ${ }^{142}$ In a separate study, Olgac at al ${ }^{143}$ investigated LDL transport from blood into arterial walls and showed that during the plaque-growing process, the location of high LDL concentration is shifted from the plaque area in the downstream direction. This result is related to the preferential direction in which the plaque will expand. Finally, Samady et al ${ }^{144}$ studied the relationship between WSS and the vulnerability of the plaque in the coronary artery. They concluded that low WSS was associated with a constrictive remodeling of the vessel, with plaque having a stable phenotype. However, high WSS was associated with an expansive remodeling, suggesting the transformation to a more vulnerable phenotype.

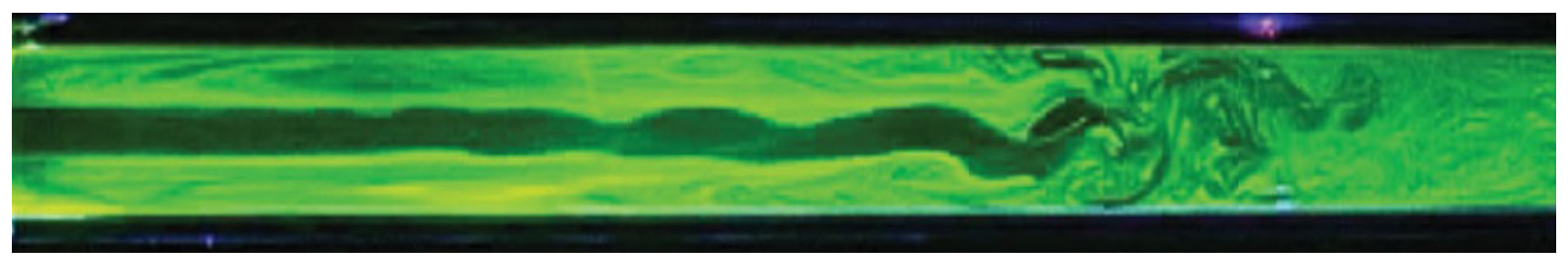

Figure 5 Experimental visualization of a turbulent flow in a perspex tube.

Notes: The trajectories are visualized downstream of an axisymmetric model stenosis by fluorescein dye. Reproduction from Griffith et al. ${ }^{134}$ 
(i)

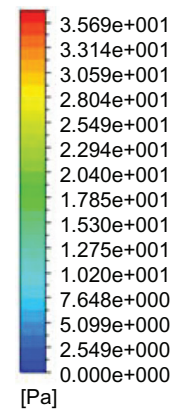

(ii)

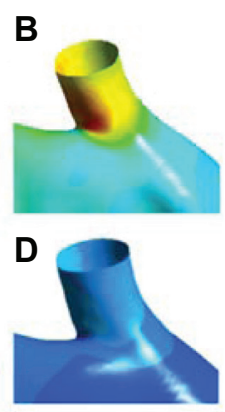

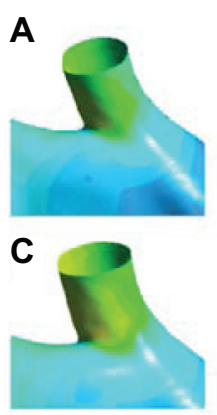
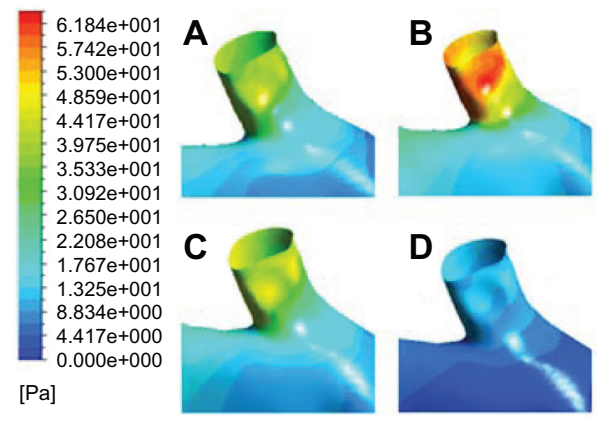

(iii)

Figure 6 WSS distribution on the brachiocephalic artery at four stages during the cardiac cycle as indicated on the volumetric flow rate diagram (iii); (a) systolic acceleration, (b) peak systole and (c and d) systolic deceleration. The vessel without plaque is presented above (i), and the vessel with plaque in the lower part of the figure (ii). Reproduction from Hough et al. ${ }^{142}$

\section{Plaque rupture}

\section{Structural stress}

Most of the computational studies that model the plaque formation discussed so far have considered the vessels as rigid walls ${ }^{41}$ and have not taken into account the effects of vessel elasticity. In reality, the vessel wall expands and contracts as the pulsatile blood passes through the arteries. Interactions between the fluid and the vessel wall and plaque play an important role in understanding plaque vulnerability. Most biomechanical models of plaque vulnerability are based on the theory that plaque rupture will occur when the tissue stress reaches a particular threshold, around $300 \mathrm{kPa} .^{50,145}$ Whilst several studies indicate a link between high WSS and plaque rupture, ${ }^{146}$ structural stresses are thought to play a more important role, being several orders of magnitude higher than WSS induced by blood flow..$^{99,145,147,148}$ Belzacq et al ${ }^{47}$ showed that the structural stress generated by the coupled artery wall motion and blood flow depended on the dimensions of the plaque, so that the stress and potentially the rupture are dependent on the remodeling. Local variation in plaque material properties can also contribute to plaque rupture, with disruption commonly observed at sites where the fibrous cap is thin. ${ }^{149}$ Teng et al ${ }^{150}$ demonstrated that the location of critical stress on the plaque surface depends on both fibrous cap thickness and arterial luminal curvature. A 3-D FSI model has revealed an association between regions of high plaque critical stress and fibrous cap disruption in human carotid plaques. ${ }^{50}$ Furthermore, maximum principal stresses were identified on shoulder regions of the fibrous caps of carotid plaques, according to the simulations of Kock et al. ${ }^{151} \mathrm{~A}$ histology-based finite element analysis was used by Vengrenyuk et al ${ }^{152}$ to investigate the peak circumferential stresses in aortic and brachiocephalic plaques of
ApoE-/- mice. Both peak and circumferential stresses in the aortic lesions were found to be significantly less than in the brachiocephalic lesions, despite only modestly larger cap thickness. They proposed that the biomechanical stresses in the brachiocephalic artery resemble human vulnerable plaques, whilst those in the aorta resemble stable lesions. ${ }^{152}$ Recently, Liu et al ${ }^{153}$ developed an approach that combines intravascular ultrasound imaging, biaxial mechanical testing, and computational modeling to study the impact of the pre-shrink-stretch process, vessel curvature and high blood pressure on stress, strain, flow velocity, and flow maximum principal shear stress. Hoskins and Hardman ${ }^{154}$ reviewed the available techniques for the estimation of structural stress in arterial diseases. To define more accurately a structural stress threshold for rupture, some studies have investigated the fracture properties of artery wall. For example, Holzapfel et al ${ }^{155}$ conducted ultimate tensile tests on iliac arteries from human subjects. They found that the lowest fracture stress occurred in the circumferential direction of the fibrous cap (254.8 \pm $79.8 \mathrm{kPa}$ at stretch $1.182 \pm 0.1$ ). In Teng et al, ${ }^{156}$ the authors investigate the ultimate strength of the adventitia and media of six human atherosclerotic carotid arteries in circumferential and axial directions. The lowest ultimate strength was found for the circumferential media with a value of $150 \mathrm{kPa}$. In a different study, Versluis et al ${ }^{157}$ considered that plaque rupture could come from a fatigue process, ie, as the culmination of a chronic injury. Finally, Hallow et al ${ }^{158}$ reported that in addition to these pure mechanical effects that describe and eventually predict plaque-rupture processes, the mechanical stress was also related to inflammatory marker expression in atherosclerotic plaques, and so could have an influence of the vulnerability of the plaque. Table 1 reports the rupture thresholds of the mechanical stresses found in the literature. 
Table I Critical rupture values for the stresses extracted from the literature

\begin{tabular}{|c|c|c|c|c|c|}
\hline References & Model & Vessel localization & Stress type & Method & Stress Threshold \\
\hline \multirow[t]{2}{*}{ Teng et al ${ }^{159}$} & Human & Carotid & Critical plaque wall stress & $\begin{array}{l}\text { MRI/histology } \\
\text { numerical }\end{array}$ & 263.44 kPa (mean) \\
\hline & & & Critical flow shear stress & & 9.29 $\mathrm{Pa}$ (no direct relation with rupture) \\
\hline Tang et $\mathrm{al}^{50}$ & Human & Carotid & Plaque wall stress & $\begin{array}{l}\text { MRI/histology } \\
\text { numerical }\end{array}$ & $247.3 \mathrm{kPa}$ \\
\hline Lawlor et al ${ }^{160}$ & Human & Carotid & Ultimate tensile stress & Uniaxial tensile tester & $|3|-779 \mathrm{kPa}$ \\
\hline Teng et al ${ }^{156}$ & Human & Carotid & Ultimate tensile stress & Uniaxial tensile tester & Media/adventitia 519-1996 kPa \\
\hline $\begin{array}{l}\text { Holzapfel } \\
\text { et al }{ }^{155}\end{array}$ & Human & Iliac artery & Ultimate tensile stress & Uniaxial tensile tester & $\begin{array}{l}179 \pm 56 \mathrm{kPa} \text { (calcification), } 254.8 \pm \\
79.8 \mathrm{kPa} \\
\text { (intima circumferemtial stress) }\end{array}$ \\
\hline $\begin{array}{l}\text { Vengrenyuk } \\
\text { et al }{ }^{152}\end{array}$ & Mouse & $\begin{array}{l}\text { Brachiocephalic } \\
\text { artery }\end{array}$ & $\begin{array}{l}\text { Tensile circumferential } \\
\text { stress }\end{array}$ & $\begin{array}{l}\text { Histology } \\
\text { numerical }\end{array}$ & $1400 \mathrm{kPa}$ \\
\hline Wang et $\mathrm{al}^{161}$ & Mouse & Aorta & Local energy-release rate & Delamination & $24.5 \mathrm{~J} / \mathrm{m}^{2}$ (mean) \\
\hline
\end{tabular}

Abbreviation: MRI, magnetic resonance imaging.

\section{Microcalcification}

In addition to the structural stress and various phenomena described in the previous section, microcalcifications are believed to play a role in rupture processes. A new hypothesis for vulnerable plaque rupture due to stress-induced debonding around cellular microcalcifications embedded in thin fibrous caps was proposed by Vengrenyuk et al. ${ }^{112}$ The mathematical model used in this study indicates that the amplitude of the structural stress found in some zones of the fibrous cap can be intensified (up to two times) in the presence of spherical inclusions. Following this work, Bluestein et al ${ }^{162}$ implemented an FSI numerical model and found that the stresses increased locally upstream of the calcification, with stress propagating in the surrounding deformable structure. This study has been completed by the recent work of Rambhia et al, ${ }^{163}$ where a coupled microcomputed tomography imaging and FSI method is used to show the increase of stresses in the fibrous cap due to calcifications. In Hoshino et al, ${ }^{164}$ a numerical and a theoretical approach is used to study the effect of rigid (calcifications) and liquid (lipid core) inclusions in a distensible material. They found that the presence of calcification can increase or decrease the structural stresses, and so have a stabilizing or destabilizing effect on the plaque, depending on their relative position to the lipid core. A similar conclusion about the ambiguous effect of calcifications was obtained by Wong et al ${ }^{165}$ in a numerical simulation of calcifications in the carotid bifurcation. Nicoll and Henein ${ }^{166}$ went further and proposed the viewing of the arterial calcification and atherosclerosis as two distinct pathologies, underlining that the reasons for their frequent coexistence are not yet well understood. In a numerical study applying FSI methods, Wenk et a ${ }^{167}$ showed that the circumferential stress in the fibrous tissue increases as the volume fraction of microcalcifications is increased. The local stress can reach a critical threshold when the fibrous cap is thin. Furthermore, they reported that the presence of microcalcifications significantly influences the distribution of stress by shifting the maximum circumferential stress away from the cap shoulders, where failure is most common. One of the most recent studies on microcalcifications in atherosclerosis was conducted by Maldonado et al, ${ }^{168}$ and consisted of an extension of the study conducted by Vengrenyuk et al, ${ }^{112}$ with an expanded number of samples. The new results included the definition of criteria for plaque vulnerability, such as the variation of the Young's modulus of the microcalcification and the surrounding tissue, threshold for stresses that induce rupture, microcalcification size, and clustering. In addition, they indicated that rupture is not associated with debonding around calcification, as previously proposed, but seems to be more related to the explosive growth of the small voids in the tissue in the vicinity of small microcalcification clusters.

Finally, calcifications are commonly found in atherosclerosis, but their distribution depends on their position in the arterial tree. In a recent study, Heymann et al, ${ }^{169}$ using endarterectomy material from human subjects, showed that calcifications are more prone to appear in femoral than in carotid plaques.

Altogether, these studies underline the complex relation between plaque rupture and microcalcifications. Further investigations seem to be necessary to elucidate this relationship.

\section{Soft plaques: hemorrhage and stress}

It was shown a few years ago that intraplaque hemorrhages played a role in the destabilization and the progression of atherosclerotic plaques. ${ }^{170,171}$ Concerning the mechanical 
effects, it has been shown more recently that zones of high structural stresses are found in intraplaque hemorrhage areas. $^{51}$ Teng et al ${ }^{172}$ performed a 2-year follow-up study of two patient groups, all suffering transient ischemic attack and developing carotid plaques. The first group corresponded to patients with juxtaluminal hemorrhage/thrombus in the carotid plaque, whereas the second group did not. It was found that the critical mechanical stretch was significantly different from one group to the other, with the first group experiencing recurrent events, whereas the second group did not. It has been proposed that juxtaluminal hemorrhage/ thrombus might be a high risk factor related with recurrent events. In Huang et al, ${ }^{173}$ the impact of hemorrhage on critical plaque-wall stress and strain has been investigated using a 3-D FSI numerical model. They showed that the presence of intraplaque hemorrhage could imply an increase of $27.5 \%$ of the structural stresses, so this phenomenon cannot be neglected when calculating rupture stress threshold.

All these studies have inherent limitations in their approach due to the fact that the elastic properties of the tissue implemented in the numerical models are not patient-specific. They also underline the limitation of spatial resolution of the MRI approach, so future studies will be necessary to determine in more detail the relation between structural stresses and intraplaque hemorrhages.

\section{Summary}

This paper, divided in two main parts, presents a review of the current mechanical models used to simulate blood flow in moving arteries with plaques, as well as a discussion on the influence of mechanical effects on plaque formation, development, and rupture processes. The first part underlines the difficulty in defining accurately mathematical models used in numerical simulations to predict plaque rupture. In addition, this part lists the physical parameters that must be determined for the implementation of numerical methods. Although this question is well documented in the literature, attention should be paid in future studies to the variation of these parameters on the time scale of the plaque development. In addition, the importance of the progress in imaging techniques has been highlighted. The second part of the paper illustrates the current knowledge of the relationship between plaque evolution and mechanical stresses. It has been demonstrated that WSS plays a dominant role in the plaque-formation process; however, the importance of other hemodynamic parameters is still a question under debate. Concerning plaque rupture, most of the studies investigate the structural stresses and aim to define a threshold characteristic of rupture. Nevertheless, the dependence of the structural stress on microcalcifications or hemorrhages is still unresolved. The less documented question is certainly the relationship between plaque development and mechanical effects. This question, of crucial importance to characterize the vulnerability of plaques, is currently being investigated by our team and others.

\section{Acknowledgments}

The authors acknowledge financial support from the Australian Research Council, under grant no DP110100434. They acknowledge their collaborators Andrea Aprico, Karen Andrews, and Jaye Chin-Dusting from the Baker IDI Heart and Diabetes Institute, and Anthony Dart from the Alfred Hospital, for providing the animal models; James Armitage, Karla Contreras, Stacey Hokke from Monash University for the genotyping of the animals, the preparation of the samples for synchrotron imaging, and histochemical analyses; Karen Siu for conducting the experiment at the Swiss Light Source. They acknowledge also Jillian Hough and Gwenael Hannema, two students involved in the project.

\section{Disclosure}

The authors report no conflicts of interest in this work.

\section{References}

1. Stoker R, Keaney JF Jr. Role of oxidative modifications in atherosclerosis. Physiol Rev. 2004;84:1381-1478.

2. Chatzizisis YS, Coskun AU, Jonas M, Edelman ER, Feldman CL, Stone PH. Role of endothelial shear stress in the natural history of coronary atherosclerosis and vascular remodeling: molecular, cellular and vascular behavior. J Am Coll Cardiol. 2007;49:2379-2393.

3. Pello OM, Silvestre C, De Pizzol M, Andrés V. A glimpse of the phenomenon of macrophage polarization during atherosclerosis. Immunobiology. 2011;216:1172-1176.

4. Newby AC, Zaltsman AB. Fibrous cap formation or destruction - the critical importance of vascular smooth muscle cell proliferation, migration and matrix formation. Cardiovasc Res. 1999;41: 345-360.

5. Arroyo AG, Iruela-Arispe ML. Extracellular matrix, inflammation, and the angiogenic response. Cardiovasc Res. 2010;86:226-235.

6. Stone PH, Coskun AU, Kinlay S, et al. Regions of low endothelial shear stress are the sites where coronary plaque progresses and vascular remodelling occurs in humans: an in vivo serial study. Eur Heart J. 2007;28:705-710.

7. Finn AV, Nakano M, Narula J, Kolodgie FD, Virmani R. Concept of vulnerable/unstable plaque. Arterioscler Thromb Vasc Biol. 2010;30: 1282-1292.

8. Reininger AJ, Bernlochner I, Penz SM, et al. A 2-step mechanism of arterial thrombus formation induced by human atherosclerotic plaques. J Am Coll Cardiol. 2010;55:1147-1158.

9. Giannakopoulos TG, Avgerinos ED, Moulakakis KG, et al. Biomarkers for diagnosis of the vulnerable atherosclerotic plaque. Interv Cardiol. 2011;3:223-233.

10. Finet G, Oyayon J, Rioufol G. Biomechanical interaction between cap thickness, lipid core composition and blood pressure in vulnerable coronary plaque: impact on stability or instability. Coron Artery Dis. 2004; 15:13-20. 
11. Ylä-Herttuala S, Fog Bentzon J, Daemen M, et al. Stabilisation of atherosclerotic plaques. Position paper of the European Society of Cardiology (ESC) Working Group on atherosclerosis and vascular biology. Thromb Haemost. 2011;106:1-19.

12. Hourigan K. Hot topic: biomedical engineering imaging [editorial]. Curr Pharm Biotechnol. 2012;13:2103.

13. Hourigan K. Frontiers in research reviews: new frontiers in biomedical engineering. Introduction. Clin Exp Pharmacol Physiol. 2009;36:192-193.

14. Fouras A, Kitchen MJ, Dubsky S, Lewis RA, Hooper SB, Hourigan K. The past, present and future X-ray technology for in vivo imaging of function and form. J Appl Phys. 2009;105:1-14.

15. Sander D, Kukla C, Klingelhöfer J, Winbeck K, Conrad B. Relationship between circadian blood pressure patterns and progression of early carotid atherosclerosis: a 3-year follow-up study. Circulation. 2000;102:1536-1541.

16. Zhang X, Zhao F, Xu C, et al. Circadian rhythm disorder of thrombosis and thrombolysis-related gene expression in apolipoprotein $\mathrm{E}$ knock-out mice. Int J Mol Med. 2008;22:149-153.

17. Shiomi M, Ito T. The Watanabe heritable hyperlipidemic (WHHL) rabbit, its characteristics and history of development: a tribute to the late Dr Yoshio Watanabe. Atherosclerosis. 2009;207:1-7.

18. Granada JF, Kaluza GL, Wilensky RL, Biedermann BC, Schwartz RS, Falk E. Porcine models of coronary atherosclerosis and vulnerable plaque for imaging and interventional research. Euro Intervention. 2009;5:140-148.

19. Bond AR, Jackson CL. The fat-fed apolipoprotein E knockout mouse brachiocephalic artery in the study of atherosclerotic plaque rupture. J Biomed Biotechnol. 2011;2011:379069.

20. Schwartz SM, Galis ZS, Rosenfeld ME, Falk E. Plaque rupture in humans and mice. Arterioscler Thromb Vasc Biol. 2007;27:705-713.

21. Jackson CL, Bennett MR, Biessen EA, Johnson JL, Krams R. Assessment of unstable atherosclerosis in mice. Arterioscler Thromb Vasc Biol. 2007;27:714-720.

22. Zhang SH, Reddick RL, Piedrahita JA, Maeda N. Spontaneous hypercholesterolemia and arterial lesions in mice lacking apolipoprotein E. Science. 1992;258:468-471.

23. Ishibashi S, Goldstein JL, Brown MS, Herz J, Burns DK. Massive xanthomatosis and atherosclerosis in cholesterol-fed low density lipoprotein receptor-negative mice. J Clin Invest. 1994;93:1885-1893.

24. Johnson JL, Jackson CL. Atherosclerotic plaque rupture in the apolipoprotein E knockout mouse. Atherosclerosis. 2001;154: 399-406.

25. Assemat P, Hough J, Siu KK, et al. Three-dimensional numerical simulation of blood flow in mouse aortic arch around atherosclerotic plaques. Paper presented at the Ninth International Conference on CFD in the Minerals and Process Industries (CSIRO); December 10-12, 2012; Melbourne, Australia.

26. Bentzon JF, Falk E. Atherosclerotic lesions in mouse and man: is it the same disease? Curr Opin Lipidol. 2010;21:434-440.

27. Jin SX, Shen LH, Nie P, et al. Endogenous renovascular hypertension combined with low shear stress induces plaque rupture in apolipoprotein E-deficient mice. Arterioscler Thromb Vasc Biol. 2012;32:2372-2379.

28. Jackson CL. Rupture of delight? A new mouse model of plaque rupture. Arterioscler Thromb Vasc Biol. 2006;26:1191-1192.

29. Clarke MCH, Figg N, Maguire JJ, et al. Apoptosis of vascular smooth muscle cells induce features of plaque vulnerability in atherosclerosis. Nat Med. 2006;12:1075-1080.

30. Ku DN. Blood flow in arteries. Annu Rev Fluid Mech. 1997;29: $399-434$

31. Feintuch A, Ruengsakulrach P, Lin A, et al. Hemodynamics in the mouse aortic arch as assessed by MRI, ultrasound, and numerical modeling. Am J Physiol Heart Circ Physiol. 2007;292:H884-H892.

32. Grinberg L, Anor T, Madsen JR, Yakhot A, Karniadakis GE. Large-scale simulation of the human arterial tree. Clin Exp Pharmacol Physiol. 2009;36:94-205.
33. Waters SL, Alastruey J, Beard DA, et al. Theoretical models for coronary vascular biomechanics: progress and challenges. Prog Biophys Mol Biol. 2011;104:49-76.

34. Westerhof N, Boer C, Lamberts RR, Sipkema P. Cross-talk between cardiac muscle and coronary vasculature. Physiol Rev. 2006;86: 1263-1308.

35. Duncker DJ, Bache RJ. Regulation of coronary blood flow during exercise. Physiol Rev. 2008;88:1009-1086.

36. Huo Y, Guo X, Kassab GS. The flow field along the entire length of the mouse aorta and primary branches. Ann Biomed Eng. 2008;36: 685-699.

37. Van Doormaal MA, Kazakidi A, Wylezinska M, et al. Haemodynamics in the mouse aortic arch computed from MRI-derived velocities at the aortic root. J R Soc Interface. 2012;9:2834-2844.

38. Zhu H, Zhang J, Shih J, et al. Differences in aortic arch geometry, hemodynamics, and plaque patterns between C57BL/6 and 129/SvEv mice. J Biomech Eng. 2009;131:1-7.

39. Trachet B, Swillens A, Van Loo D, et al. The influence of aortic dimensions on calculated wall shear stress in the mouse aortic arch. Comput Methods Biomech Biomed Engin. 2009;12:491-499.

40. Janssen B, Debets J, Leenders P, Smits J. Chronic measurement of cardiac output in conscious mice. Am J Physiol Regul Integr Comp Physiol. 2002;282:R928-R935.

41. Vasava P, Jalali P, Dabagh M, Kolari PJ. Finite element modelling of pulsatile blood flow in idealized model of human aortic arch: study of hypotension and hypertension. Comput Math Methods Med. 2012;2012: $1-14$.

42. Trachet B, Bols J, De Santis G, Vandenberghe S, Loeys B, Segers P. The impact of simplified boundary conditions and aortic arch inclusion on CFD simulation in the mouse aorta: a comparison with mouse-specific reference data. J Biomech Eng. 2011;133:121006.

43. Lantz J, Renner J, Karlsson M. Wall shear stress in a subject specific human aorta - influence of fluid-structure interaction. Int J Appl Mech. 2011;4:759-778.

44. Westerhof N, Lankhaar JW, Westerhof BE. The arterial Windkessel. Med Biol Eng Comput. 2009;47:131-141.

45. Moireau P, Xiao N, Astorino M, et al. External tissue support and fluid-structure simulation in blood flow. Biomech Model Mechanobiol. 2012;11:1-18

46. Chen JL, Wang SZ, Ding GH, Yang XJ, Li HY. The effect of aneurismalwall mechanical properties on patient-specific hemodynamic simulations: two clinical case reports. Acta Mech Sin. 2009;25:677-688.

47. Belzacq T, Avril S, Leriche E, Delache A. A numerical parametric study of the mechanical action of pulsatile blood flow onto axisymmetric stenosed arteries. Med Eng Phys. 2012;34:1483-1495.

48. Assemat P, Hannema GW, Siu KK, et al. Hypertension and atherosclerotic plaque: a fluid structure interaction approach. J Hypertens. 2012;30:e81.

49. Tang D, Yang C, Zheng J, et al. Quantifying effects of plaque structure and material properties on stress distributions in human atherosclerotic plaques using 3D FSI models. J Biomech Eng. 2005;127: 1185-1194.

50. Tang D, Teng Z, Canton G, et al. Sites of rupture in human atherosclerotic carotid plaques are associated with high structural stresses: an in vivo MRI-based 3D fluid-structure interaction study. Stroke. 2009;40:3258-3263.

51. Huang X, Teng Z, Canton G, Ferguson M, Yuan C, Tang D. Intraplaque hemorrhage is associated with higher structural stresses in human atherosclerotic plaques: an in vivo MRI-based 3D fluid-structure interaction study. Biomed Eng Online. 2010;9:86.

52. Leach JR, Rayz VL, Soares B, Wintermark M, Mofrad MR, Saloner D. Carotid atheroma rupture observed in vivo and FSI-predicted stress distribution based on pre-rupture imaging. Ann Biomed Eng. 2010;38: 2748-2765.

53. Zheng X, Seo JH, Vedula V, Abraham T, Mittal R. Computational modeling and analysis of intracardiac flows in simple models of the left ventricle. Eur J Mech B Fluids. 2012;35:31-39. 
54. Lee KW, Wood NB, Xu XY. Ultrasound image-based computer model of a common carotid artery with a plaque. Med Eng Phys. 2004;26: 823-840.

55. Farmakis TM, Soulis JV, Giannoglou GD, Zioupos GJ, Louridas GE. Wall shear stress gradient topography in the normal left coronary arterial tree: possible implications for atherogenesis. Curr Med Res Opin. 2004;20:587-596.

56. Lee SE, Lee SW, Fischer PF, Bassiouny HS, Loth F. Direct numerical simulation of transitional flow in a stenosed carotid bifurcation. J Biomech. 2008;41:2551-2561.

57. Suo J, Ferrara DE, Sorescu D, Guldberg RE, Taylor WR, Giddens DP. Hemodynamic shear stresses in mouse aortas implications for atherogenesis. Arterioscler Thromb Vasc Biol. 2007;27:346-351.

58. Hoi Y, Zhou YQ, Zhang X, Henkelman RM, Steinman DA. Correlation between local hemodynamics and lesion distribution in a novel aortic regurgitation murine model of atherosclerosis. Ann Biomed Eng. 2011;39:1414-1422.

59. Fleg JL, Stone GW, Fayad ZA, et al. Detection of high-risk atherosclerotic plaque: report of the NHLBI working group on current status and future directions. JACC Cardiovasc Imaging. 2012;5:941-955.

60. Harloff A, Nussbaumer A, Bauer S, et al. In vivo assessment of wall shear stress in the atherosclerotic aorta using flow-sensitive 4D MRI. Magn Reson Med. 2010;63:1529-1536.

61. Jin S, Oshinski J, Giddens DP. Effects of wall motion and compliance on flow patterns in the ascending aorta. J Biomech Eng. 2003;125:347-354.

62. LaDisa JF Jr, Alberto Figueroa C, Vignon-Clementel IE, et al. Computational simulations for aortic coarctation: representative results from a sampling of patients. J Biomech Eng. 2011;133:091008.

63. Mark1 M, Wegent F, Zech T, et al. In vivo wall shear stress distribution in the carotid artery: effect of bifurcation geometry, internal carotid artery stenosis, and recanalization therapy. Circ Cardiovasc Imaging. 2010;3:647-655.

64. Stalder AF, Frydrychowick A, Russe MF, et al. Assessment of flow instabilities in the healthy aorta using flow sensitive MRI. JMagn Reson Imaging. 2011;33:839-846.

65. Fouras A, Kitchen MJ, Dubsky S, Lewis RA, Hooper SB, Hourigan K. The past, present, and future of X-ray technology for in vivo imaging of function and form. J Appl Phys. 2009;105:102009.

66. Hoffmann MH, Shi H, Manzke R, et al. Noninvasive coronary angiography with 16-detector row CT: effect of heart rate. Radiology. 2005;234:86-97.

67. Schwenke DO, Pearson JT, Kangawa K, Umetani K, Shirai M. Changes in macrovessel pulmonary blood flow distribution following chronic hypoxia: assessed using synchrotron radiation microangiography. J Appl Physiol. 2008;104:88-96.

68. Dubsky S, Hooper SB, Siu KK, Fouras A. Synchrotron-based dynamic computed tomography of tissue motion for regional lung function measurement. J R Soc Interface. 2012;9:2213-2224.

69. McAteer MA, Schneider JE, Clarke K, Neubauer S, Channon KM, Choudhury RP. Quantification and 3D reconstruction of atherosclerotic plaque components in apolipoprotein E knockout mice using ex vivo highresolution MRI. Arterioscler Thromb Vasc Biol. 2004;24:2384-2390.

70. Schneider E Jr, McAteer MA, Tyler DJ, et al. High-resolution, multicontrast three-dimensional-MRI characterizes atherosclerotic plaque composition in ApoE-/- mice ex vivo. J Magn Reson Imaging. 2004;20:981-989.

71. Yu SS, Ortega RA, Reagan BW, McPherson JA, Sung HJ, Giorgio TD. Emerging applications of nanotechnology for the diagnosis and management of vulnerable atherosclerotic plaques. Wiley Interdiscip Rev Nanomed Nanobiotechnol. 2011;3:620-646.

72. Heeren J, Bruns O. Nanocrystals, a new tool to study lipoprotein metabolism and atherosclerosis. Curr Pharm Biotech. 2012;13:365-372.

73. Lantz J, Karlsson M. Large eddy simulation of LDL surface concentration in a subject specific human aorta. J Biomech. 2012;45:537-542.

74. Tomita H, Hagaman J, Friedman MH, Maeda N. Relationship between hemodynamics and atherosclerosis in aortic arches of apolipoprotein E-null mice on 129S6/SvEvTac and C57BL/6J genetic backgrounds. Atherosclerosis. 2012;220:78-85.
75. Cutnell JD, Johnson KW. Physics, 4th ed. Mississauga (ON): John Wiley and Sons Canada; 1998.

76. Ruengsakulrach P, Joshi AK, Fremes S, et al. Wall shear stress and atherosclerosis: numerical blood flow simulations in the mouse aortic arch. WSEAS Trans Fluid Mech. 2008;3:90-100.

77. Siddiqui SU, Verma NK, Mishra S, Gupta RS. Mathematical modelling of pulsatile flow of Casson's fluid in arterial stenosis. Appl Math Comput. 2009;210:1-10.

78. Ryou HS, Kim S, Kim SW, Cho SW. Construction of healthy arteries using computed tomography and virtual histology intravascular ultrasound. J Biomech. 2012;45:1612-1618.

79. Ro KC, Lee SH, Cho SW, Ryou HS. Numerical study on blood flow characteristics of the stenosed blood vessel with periodic acceleration and rotating effect. Springer Proc Phys. 2008;124:77-84.

80. Cho YI, Back LH, Crawford DW. Experimental investigation of branch flow ratio, angle, and Reynolds number effects on the pressure and flow fields in arterial branch models. J Biomed Eng. 1985;107:257-267.

81. Liu X, Fan Y, Deng X, Zhan F. Effect of non-Newtonian and pulsatile blood flow on mass transport in human aorta. J Biomech. 2011;44: 1123-1131.

82. Johnston BM, Johnston PR, Corney S, Kilpatrick D. Non-Newtonian blood flow in human right coronary arteries: steady state simulations. J Biomech. 2004;37:709-720.

83. Wells RE, Merrill JW, Merrill EW. Shear rate dependence of the viscosity of whole blood and plasma. Science. 1961;133:763-764.

84. Peacock J, Jones T, Tock C, Lutz R. The onset of turbulence in physiological pulsatile flow in a straight tube. Exp Fluid. 1998;24:1-9.

85. Lantz J, Gardhagen R, Karlsson M. Quantifying turbulent wall shear stress in a subject specific human aorta using large eddy simulation. Med Eng Phys. 2012;34:1139-1148.

86. Shinohara M, Yamashita T, Tawa H, et al. Atherosclerotic plaque imaging using phase-contrast X-ray computed tomography. Am J Physiol Heart Circ Physiol. 2008;294:H1094-H1100.

87. Sommer G. Mechanical Properties of Healthy and Diseased Human Arteries: Insights into Human Arterial Biomechanics and Related Material Modeling. Graz, Austria: Verlag der Technischen Universität Graz; 2010.

88. Dobrin PB. Mechanical properties of arteries. Physiol Rev. 1978;58: 397-460.

89. Fung YC. Biomechanics: Mechanical Properties of Living Tissues, 2nd ed. New York: Springer-Verlag; 1993.

90. Fung YC. Inversion of a class of nonlinear stress-strain relationships of biological soft tissues. J Biomech Eng. 1979;101:23-27.

91. Fung YC, Liu SQ. Strain distribution in small blood vessels with zero stress state taken into consideration. Am J Physiol. 1992;262:H544-H552.

92. Lee AY, Han B, Lamm SD, Fierro CA, Han HC. Effects of elastin degradation and surrounding matrix support on artery stability. Am J Physiol Heart Circ Physiol. 2012;302:H873-H884.

93. Holzapfel GA, Gasser TC, Ogden RW. A new constitutive framework for arterial wall mechanics and a comparative study of material models. J Elasticity. 2000;61:1-48.

94. Raghavan ML, Trivedi S, Nagaraj A, McPherson DD, Chandran KB. Three-dimensional finite element analysis of residual stress in arteries. Ann Biomed Eng. 2004;32:257-263.

95. Martinez R, Fierro CA, Shireman PK, Han HC. Mechanical buckling of veins under internal pressure. Ann Biomed Eng. 2010;38:1345-1353.

96. Chuong C, Fung Y. Blood vessel buckling within soft surrounding tissue generates tortuosity. J Biomech Eng. 1983;42:2797-2801.

97. Mooney M. A theory of large elastic deformation. J Appl Phys. 1940;11:582-593.

98. Rivlin RS. Large elastic deformations of isotropic materials. iv. Further developments of the general theory. Philos Trans $R$ Soc Lond B. 1948;241:379-397.

99. Yang C, Bach RG, Zheng J, et al. In vivo IVUS-based 3-D fluid-structure interaction models with cyclic bending and anisotropic vessel properties for human atherosclerotic coronary plaque mechanical analysis. IEEE Trans Biomed Eng. 2009;56:2420-2428. 
100. Takamizawa K, Hayashi K. Strain energy density function and uniform strain hypothesis for arterial mechanics. J Biomech. 1987;20:7-17.

101. Humphrey JD. An evaluation of pseudoelastic descriptors used in arterial mechanics. J Biomech Eng. 1999;121:259-262.

102. Wuyts FL, Vanhuyse VJ, Langewouters GJ, Decraemer WF, Raman ER, Buyle S. Elastic properties of human aortas in relation to age and atherosclerosis: a structural model. Phys Med Biol. 1995;40:1577-1597.

103. Zulliger MA, Fridez P, Hayashi K, Stergiopulos N. A strain energy function for arteries accounting for wall composition and structure. J Biomech. 2004:37:989-1000.

104. Zulliger MA, Stergiopulos N. Structural strain energy function applied to the ageing of the human aorta. J Biomech. 2007;40: 3061-3069.

105. Astrand H, Stalhand J, Karlsson J, Karlsson M, Sonesson B, Länne T. In vivo estimation of the contribution of elastin and collagen to the mechanical properties in human aorta: effect of age and sex. $J$ Appl Physiol. 2011;110:176-187.

106. Valentin A, Humphrey JD, Holzapfel GA. A multi-layered computational model of coupled elastin degradation, vasoactive dysfunction and collagenous stiffening in aortic aging. 2011;39: 2027-2045

107. Xie J, Zhou J, Fung YC. Bending of blood vessel wall: stress-strain laws of the intima-media and adventitial layers. $J$ Biomech Eng. 1995;117:136-145.

108. Von Maltzahn WW, Besdo D, Wiemer W, Elastic properties of arteries: a nonlinear two-layer cylindrical model. J Biomech. 1981;14:389-397.

109. Demiray H. A layered cylindrical shell model for an aorta. Int J Eng Sci. 1991;29:47-54.

110. Topoleski LD, Salunke NV. Mechanical behaviour of calcified plaques: a summary of compression and stress-relaxation experiments. Z Kardiol. 2000;89 Suppl 2:85-91.

111. Loree HM, Grodzinsky AJ, Park SY, Gibson LJ, Lee RT. Static circumferential tangential modulus of human atherosclerotic tissue. J Biomech. 1994;27:195-204.

112. Vengrenyuk Y, Carlier S, Xanthos S, et al. A hypothesis for vulnerable plaque rupture due to stress-induced debonding around cellular microcalcifications in thin fibrous caps. Proc Natl Acad Sci U S A. 2006;103:14678-14683.

113. Matsumoto T, Goto T, Furukawa T, Sato M. Residual stress and strain in the lamellar unit of the porcine aorta: experiment and analysis. J Biomech. 2004;37:807-815.

114. Oie T, Murayama Y, Fukuda T, et al. Local elasticity imaging of vascular tissues using a tactile mapping system. J Artif Organs. 2009; 12:40-46.

115. Hayenga HN, Trache A, Trzeciakowski J, Humphrey JD. Regional atherosclerotic plaque properties in ApoE-/- mice quantified by atomic force, immunofluorescence, and light microscopy. J Vasc Res. 2011;48:495-504.

116. Tracqui P, Broisat A, Toczek J, Mesnier N, Ohayon J, Riou L. Mapping elasticity moduli of atherosclerotic plaque in situ via atomic force microscopy. J Struct Biol. 2011;174:115-123.

117. Stone PH, Saito S, Takahashi S, et al. Prediction of progression of coronary artery disease and clinical outcomes using vascular profiling of endothelial shear stress and arterial plaque characteristics: the PREDICTION study. Circulation. 2012;126:172-181.

118. Cheng C, Tempel D, Van Haperen R, et al. Atherosclerotic lesion size and vulnerability are determined by patterns of fluid shear stress Circulation. 2006;113:2744-2753.

119. Caro CG, Fitz-Gerald JM, Schroter RC. Atheroma and arterial wall shear. Observation, correlation and proposal of a shear dependent mass transfer mechanism for atherogenesis. Proc R Soc Lond B Biol Sci. 1971;177:109-133.

120. Gibson CM, Diaz L, Kandarpa K, et al. Relation of vessel wall shear stress to atherosclerosis progression in human coronary arteries. Arterioscler Thromb. 1993;13:310-315.
121. Stone PH, Coskun AU, Kinlay S, et al. Regions of low endothelial shear stress are the sites where coronary plaque progresses and vascular remodelling occurs in humans: an in vivo serial study. Eur Heart $J$. 2007;28:705-710.

122. van Bochove GS, Straathof R, Krams R, Nicolay K, Strijkers GJ. MRI-determined carotid artery flow velocities and wall shear stress in a mouse model of vulnerable and stable atherosclerotic plaque. MAGMA. 2010;23:77-84.

123. Warboys CM, Berson RE, Mann GE, Pearson JD, Weinberg PD. Acute and chronic exposure to shear stress have opposite effects on endothelial permeability to macromolecules. Am J Physiol Heart Circ Physiol. 2010;298:H1850-H1856.

124. Ku DN, Giddens DP, Zarins CK, Glagov S. Pulsatile flow and atherosclerosis in the human carotid bifurcation. Positive correlation between plaque location and low oscillating shear stress. Arteriosclerosis. 1985;5:293-302.

125. Thim T, Hagensen MK, Hørlyck A, et al. Wall shear stress and local plaque development in stenosed carotid arteries of hypercholesterolemic minipigs. J Cardiovasc Dis Res. 2012;3:76-83.

126. Rikhtegar F, Knight JA, Olgac U, et al. Choosing the optimal wall shear parameter for the prediction of plaque location - a patient-specific computational study in human left coronary arteries. Atherosclerosis. 2012;221:432-437.

127. DePaola N, Gimbrone MA Jr, Davies PF, Dewey CF Jr. Vascular endothelium responds to fluid shear stress gradients. Arterioscler Thromb. 1991;12:1254-1257.

128. Chiu JJ, Chien S. Effects of disturbed flow on vascular endothelium: pathophysiological basis and clinical perspectives. Physiol Rev. 2011;91:327-387.

129. Lei M, Kleinstreuer C, Truskey GA. Numerical investigation and prediction of atherogenic sites in branching arteries. $J$ Biomech Eng. 1995;117:350-357.

130. Michell DL, Andrews KL, Woollard KJ, Chin-Dusting JP. Imaging leukocyte adhesion to the vascular endothelium at high intraluminal pressure. J Vis Exp. 2011;54:e3221.

131. Lawrence-Brown M, Stanley BM, Sun Z, et al. Stress and strain behaviour modelling of the carotid bifurcation. ANZ J Surg. 2011;81:810-816.

132. Griffith MD, Leweke T, Thompson MC, Hourigan K. Steady inlet flow in stenotic geometries: convective and absolute instabilities. $J$ Fluid Mech. 2008;616:111-133.

133. Griffith MD, Leweke T, Thompson MC, Hourigan K. Pulsatile flow in stenotic geometries: flow behaviour and stability. J Fluid Mech 2009;622:291-320.

134. Griffith MD, Thompson MC, Leweke T, Hourigan K. Convective instability in steady stenotic flow: optimal transient growth and experimental observation. J Fluid Mech. 2010;655:504-514.

135. Sherwin SJ, Blackburn HM. Three-dimensional instabilities and transition of steady and pulsatile axisymmetric stenotic flows. J Fluid Mech. 2005;533:297-327.

136. Blackburn HM, Sherwin SJ. Instability modes and transition of pulsatile stenotic flow: pulse-period dependence. J Fluid Mech. 2007;573:57-88

137. Mao X, Sherwin SJ, Blackburn HM. Transient growth and bypass transition in stenotic flow with a physiological waveform. Theor Comput Fluid Dyn. 2011;25:31-42.

138. Jamison RA, Dubsky S, Siu KK, Hourigan K, Fouras A. X-ray velocimetry and haemodynamic forces within a stenosed femoral model at physiological flow rates. Ann Biomed Eng. 2011;39: $1643-1653$

139. Dubsky S, Jamison R, Higgins S, Siu KKW, Hourigan K, Fouras A. Computed tomographic X-ray velocity for simultaneous 3D measurement of velocity and geometry in opaque vessels. Exp Fluids. 2012;52:543-554.

140. Chaichana T, Sun Z, Jewkes J. Computational fluid dynamics analysis of the effect of plaques on the left coronary artery. Comput Math Methods Med. 2012;2012:1-9. 
141. Chaichana T, Sun Z, Jewkes J. Impacts of plaques in the left coronary artery on wall shear stress and pressure gradient in coronary side branches. Comput Methods Biomech Biomed Engin. 2012;2012:1-11.

142. Hough JP, Assemat P, Siu KK, et al. Three-dimensional numerical simulations of pulsatile blood flow in the mouse aortic arch around atherosclerotic plaques. In: Brandner PA, Pearce BW. Proceedings of the Eighteenth Australasian Fluid Mechanics Conference; December 3-7, 2012; Launceston, Australia. Melbourne: Australasian Fluid Mechanics Society; 2012.

143. Olgac U, Poulikakos D, Saur SC, Alkadhi H, Kurtcuoglu V. Patientspecific three-dimensional simulation of LDL accumulation in a human left coronary artery in its healthy and atherosclerotic states. Am J Physiol Heart Circ Physiol. 2009;296:H1969-H1982.

144. Samady H, Eshtehardi P, McDaniel MC, et al. Coronary artery wall shear stress is associated with progression and transformation of atherosclerotic plaque and arterial remodeling in patients with coronary artery disease. Circulation. 2011;124:779-788.

145. Sadat U, Teng Z, Gillard JH. Biomechanical structural stresses of atherosclerotic plaques. Expert Rev Cardiovasc Ther. 2010;8:1469-1481.

146. Groen HC, Gijsen FJH, Van Der Lugt A, et al. Plaque rupture in the carotid artery is localized at the high shear stress region. Stroke. 2007;38:2379-2381.

147. Dolla WJ, House JA, Marso SP. Stratification of risk in thin cap fibroatheromas using peak plaque stress estimates from idealized finite element models. Med Eng Phys. 2012;34:1330-1338.

148. Li ZY, Taviani V, Tang T, et al. The mechanical triggers of plaque rupture: shear stress vs pressure gradient. Br J Radiol. 2009;82:S39-S45.

149. Li ZY, Howarth SPS, Tang T. How critical is fibrous cap thickness to carotid plaque stability? A flow-plaque interaction model. Stroke. 2006;37:1195-1199.

150. Teng Z, Sadat U, Li Z, et al. Arterial luminal curvature and fibrouscap thickness affect critical stress conditions within atherosclerotic plaque: an in vivo MRI-based 2D finite-element study. Ann Biomed Eng. 2010;38:3096-3101.

151. Kock SA, Nygaard JV, Eldrup N, et al. Mechanical stresses in carotid plaques using MRI-based fluid-structure interaction models. J Biomech. 2008;41:1651-1658.

152. Vengrenyuk Y, Kaplan TJ, Cardoso L, Randolph GJ, Weinbaum S. Computational stress analysis of atherosclerotic plaques in ApoE knockout mice. Ann Biomed Eng. 2010;38:738-747.

153. Liu H, Cai M, Yang C. IVUS-based computational modeling and planar biaxial artery material properties for human coronary plaque vulnerability assessment. Mol Cell Biomech. 2012;9:77-93.

154. Hoskins PR, Hardman D. Three-dimensional imaging and computational modelling for estimation of wall stresses in arteries. Br J Radiol. 2009;82:S3-S17.

155. Holzapfel GA, Sommer G, Regitnig P. Anisotropic mechanical properties of tissue components in human atherosclerotic plaques. J Biomech Eng. 2004;126:657-665.

156. Teng Z, Tang D, Zheng J, Woodard PK, Hoffman AH. An experimental study on the ultimate strength of the adventitia and media of human atherosclerotic carotid arteries in circumferential and axial directions. J Biomech. 2009;42:2535-2539.

157. Versluis A, Bank AJ, Douglas WH. Fatigue and plaque rupture in myocardial infarction. J Biomech. 2006;39:339-347.
158. Hallow KM, Taylor WR, Rachev A, Vito RP. Markers of inflammation collocate with increased wall stress in human coronary arterial plaque. Biomech Model Mechanobiol. 2009;8:473-486.

159. Teng Z, Canton G, Yuan C, et al. 3D critical plaque wall stress is a better predictor of carotid plaque rupture sites than flow shear stress: an in vivo MRI-based 3D FSI study. J Biomech Eng. 2010;132:031007.

160. Lawlor MG, O’Donnell MR, O’Connell BM, Walsh MT. Experimental determination of circumferential properties of fresh carotid artery plaques. J Biomech. 2011;44:1709-1715.

161. Wang Y, Ning J, Johnson JA, Sutton MA, Lessner SM. Development of a quantitative mechanical test of atherosclerotic plaque stability. J Biomech. 2011;44:2439-2445.

162. Bluestein D, Alemua Y, Avrahami I, et al. Influence of microcalcifications on vulnerable plaque mechanics using FSI modeling. J Biomech. 2008;41:1111-1118.

163. Rambhia SH, Liang X, Xenos M, et al. Microcalcifications increase coronary vulnerable plaque rupture potential: a patient-based micro-CT fluid-structure interaction study. Ann Biomed Eng. 2012;40:1443-1454.

164. Hoshino T, Chow LA, Hsu JJ, et al. Mechanical stress analysis of a rigid inclusion in distensible material: a model of atherosclerotic calcification and plaque vulnerability. Am J Physiol Heart Circ Physiol. 2009;297:H802-H810.

165. Wong KKL, Thavornpattanapong P, Cheung SCP. Effect of calcification on the mechanical stability of plaque based on a three dimensional cardiol bifuncation model. BMC Cardiovasc Disord. 2012;12:7-1-18.

166. Nicoll R, Henein MY. Arterial calcification: friend or foe? Int J Cardiol. Epub July 16, 2012.

167. Wenk JF, Papadopoulous P, Zohdi TI. Numerical modeling of stress in stenotic arteries with microcalcifications: a micromechanical approximation. J Biomech Eng. 2010;132:091011.

168. Maldonado N, Kelly-Arnold A, Vengrenyuk Y, et al. A mechanistic analysis of the role of microcalcifications in atherosclerotic plaque stability: potential implications for plaque rupture. Am J Physiol Heart Circ Physiol. 2012;303:H619-H628.

169. Heymann MF, Herisson F, Davaine JM, et al. Role of the OPG/RANK/ RANKL triad in calcifications of the atheromatous plaques: comparison between carotid and femoral beds. Cytokine. 2012;58:300-306.

170. Takaya N, Yuan C, Chu BB, et al. Presence of intraplaque hemorrhage stimulates progression of carotid atherosclerotic plaques: a high-resolution magnetic resonance imaging study. Circulation. 2005;111:2768-2775.

171. Takaya N, Yuan C, Chu BB, et al. Association between carotid plaque characteristics and subsequent ischemic cerebrovascular events: a prospective assessment with MRI - initial results. Stroke. 2006;37:818-823.

172. Teng Z, Sadat U, Huang Y, et al. In vivo MRI-based 3D mechanical stress-strain profiles of carotid plaques with juxtaluminal plaque haemorrhage: an exploratory study for the mechanism of subsequent cerebrovascular events. Eur J Vasc Endovasc Surg. 2011;42: $427-433$

173. Huang X, Yang C, Canton G, Ferguson M, Yuan C, Tang D. Quantifying effect of intraplaque hemorrhage on critical plaque wall stress in human atherosclerotic plaques using three-dimensional fluidstructure interaction models. J Biomech Eng. 2012;134:121004.
ChronoPhysiology and Therapy

\section{Publish your work in this journal}

ChronoPhysiology and Therapy is an international, peer-reviewed, open access journal focusing on research into the cyclic variations and rhythmicity in physiological processes in the body and the research and development and optimal timing of administration of therapeutic targets to achieve improved outcomes and quality of life for the patient. The

\section{Dovepress}

manuscript management system is completely online and includes a very quick and fair peer-review system. Visit http://www.dovepress.com/ testimonials.php to read real quotes from published authors. 